\title{
Gut microbiota: a potential target for traditional Chinese medicine intervention in coronary heart disease
}

Tian-Yi Cheng ${ }^{\dagger}$, Jia-Xin Li ${ }^{\dagger}$, Jing-Yi Chen, Pei-Ying Chen, Lin-Rui Ma, Gui-Lin Zhang ${ }^{* \dagger}$ and Pei-Yu Yan ${ }^{* \dagger}$

\begin{abstract}
Coronary heart disease (CHD) is a common ischaemic heart disease whose pathological mechanism has not been fully elucidated. Single target drugs, such as antiplatelet aggregation, coronary artery dilation and lipid-lowering medicines, can relieve some symptoms clinically but cannot effectively prevent and treat CHD. Accumulating evidence has revealed that alterations in GM composition, diversity, and richness are associated with the risk of CHD. The metabolites of the gut microbiota (GM), including trimethylamine N-oxide (TMAO), short-chain fatty acids (SCFAs) and bile acids (BAs), affect human physiology by activating numerous signalling pathways. Due to the advantage of multiple components and multiple targets, traditional Chinese medicine (TCM) can intervene in CHD by regulating the composition of the GM, reducing TMAO, increasing SCFAs and other CHD interventions. We have searched PubMed, Web of science, Google Scholar Science Direct, and China National Knowledge Infrastructure (CNKI), with the use of the keywords "gut microbiota, gut flora, traditional Chinese medicine, herbal medicine, coronary heart disease". This review investigated the relationship between GM and CHD, as well as the intervention of TCM in CHD and GM, and aims to provide valuable insights for the treatments of CHD by TCM.
\end{abstract}

Keywords: Coronary heart disease, Gut microbiota, Traditional Chinese medicine

\section{Background}

Currently, cardiovascular disease (CVD) has become the leading cause of death globally. An estimated 17.9 million people died from CVD in 2019, representing 32\% of all global deaths [1]. There are approximately 290 million CVD patients, of whom 11 million suffer from coronary heart disease (CHD) [2]. Hypertension, diabetes, dyslipidaemia, obesity, inflammation, smoking, alcohol consumption, insufficient fruit and vegetable intake, lack of physical activity, and high psychosocial pressure

\footnotetext{
*Correspondence: glzhang@must.edu.mo; pyyan@must.edu.mo

${ }^{\top}$ Tian-Yi Cheng and Jia-Xin Li made equal contributions to this work and are co-first authors. Pei-Yu Yan and Gui-Lin Zhang are co-corresponding authors.

Faculty of Chinese Medicine, State Key Laboratory of Quality Research in Chinese Medicines, Macau University of Science and Technology, Macau, People's Republic of China
}

are the main risk factors for the occurrence and development of CHD $[3,4]$. In recent years, novel drugs such as nicorandil, ivabradine, and trimetazidine have been developed. The combination of interventional therapy and drugs has been developed, including revascularization therapy and drug-eluting stents. These treatments can effectively relieve the symptoms of patients but can hardly prevent the progression of CHD. However, with advances in metagenome technology and ribonucleic acid sequencing technology metagenome technology, accumulating evidence has revealed that the gut microbiota (GM) is associated with CHD and its risk factors. It is estimated that modulating the GM will become an emerging therapeutic strategy for the prevention of CHD.

Because of its multitarget, multichannel and multicomponent synergistic action, traditional Chinese medicine (TCM) has been used to treat CHD for thousand years. original author(s) and the source, provide a link to the Creative Commons licence, and indicate if changes were made. The images or other third party material in this article are included in the article's Creative Commons licence, unless indicated otherwise in a credit line to the material. If material is not included in the article's Creative Commons licence and your intended use is not permitted by statutory regulation or exceeds the permitted use, you will need to obtain permission directly from the copyright holder. To view a copy of this licence, visit http://creativecommons.org/licenses/by/4.0/. The Creative Commons Public Domain Dedication waiver (http://creativeco mmons.org/publicdomain/zero/1.0/) applies to the data made available in this article, unless otherwise stated in a credit line to the data. 
Recent studies have found that TCM has outstanding curative effects on CHD by regulating the GM, which provides a new therapeutic target for the prevention and treatment of $\mathrm{CHD}$ in the future.

\section{Composition and metabolites of GM affect the occurrence of CHD}

GM is a general term for microbes existing in the human gut, consisting of more than 1000 species of bacteria and $1 \times 10^{14}$ communities [5], including Firmicutes, Actinobacteria, Bacteroidetes, Proteobacteria, Verrucomicrobia, etc. Among them, Firmicutes and Bacteroidetes are the dominant strains [6]. According to pathogenicity, GM is split into probiotics, opportunistic pathogens and pathogenic bacteria. The balance of probiotics and pathogeneticbacteria can protect the intestinal mucosal barrier, help the body intake nutrients, coordinate metabolism and immunity, and prevent pathogenic microorganisms from invading the body [7]. At the same time, GM can affect human health through its metabolites, such as trimethylamine $\mathrm{N}$-oxide (TMAO), short-chain fatty acids (SCFAs) and bile acids (BAs). These metabolites act as signalling molecules to regulate metabolism and the inflammatory response in CHD patients [8].

\section{The composition of GM affects the occurrence of CHD}

Aberrant compositional changes in GM are associated with the onset and progression of CHD. According to the Gmrepo database [9], it performed a metagenome-wide association study on stools from individuals with atherosclerotic cardiovascular disease and healthy controls (Fig. 1). A clinical study involving atherosclerotic patients $(n=218)$ and healthy people $(n=187)$ corroborated the approximate results. The study described a higher abundance of Enterobacteriaceae, Solobacterium moorei, and Enterobacter aerogenes along with Atopobium parvulum, Streptococcus spp. and Lactobacillus salivarius in atherosclerotic patients. In contrast, a relative decrease in Bacteroides, Roseburia intestinalis, Prevotella and Faecalibacterium cf. prausnitzii was detected in atherosclerotic patients [10]. Another comparative study conducted

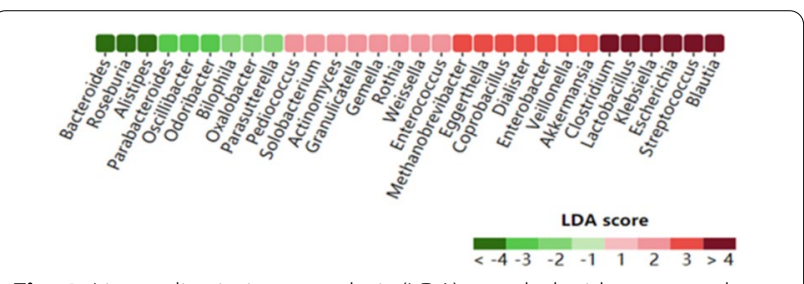

Fig. 1 Linear discriminant analysis (LDA) coupled with coronary heart disease and gut microbiota. (Marker taxa with LDA $<0$ are Health enriched, while those with LDA $>0$ are cardiovascular diseases enriched.) in CHD patients $(\mathrm{n}=29)$ and 35 healthy volunteers revealed a significant increase in the proportion of Firmicutes and a decrease in Bacteroidetes [11]. This characteristic change was also identified in a clinical study in which Firmicutes was increased and Bacteroidetes was decreased in CHD patients [12]. Accordingly, it has been proposed that the Firmicutes/Bacteroidetes (F/B) ratio is considered a biomarker of gut dysbiosis and a diagnostic marker to identify CHD patients [13, 14]. Firmicutes can ferment intake food, while Bacteroidetes is responsible for absorbing and degrading polysaccharides $[15$, 16]. An animal experiment investigated that after transplanting obese germ-free mice with higher profusion of Firmicutes and nonobese mice with higher abundance of Bacteroides, the obese recipient had a higher dietary energy harvesting ability [17]. Increasing capacity for energy harvesting but poorer degradtion will result in higher intake of fat. In addition, Firmicutes was enriched due to high fat intake, generating a vicious cycle and leading to endotoxins and inflammation, while Bacteroidetes showed the opposite effect [18-20]. The beneficial function of Bacteroidetes in CHD was further authenticated in an animal experiment [21], which indicated that the increase in Bacteroides vulgatus and Bacteroides dorei could effectively decrease lipopolysaccharides and suppress proinflammatory immune responses.

More studies have demonstrated that alterations in GM could affect metabolic risk factors for CHD. Actinobacteria are considered to have a negative correlation with cholesterol. An increase in Actinobacteria reduced atherogenic lipid metabolites, proinflammatory cytokines and atherosclerotic lesions [22, 23]. Prevotella copri and Bifidobacteria positively ameliorated glucose tolerance, alleviating the development of CHD [24]25. Bifidobacteria play a beneficial role, giving the rein a reduction in AS. Eubacterium was positively connected with enhanced visceral fat mass in people and higher TMAO levels [26], while Bifidobacteria displayed an inverse relationship to Eubacterium, reducing lipid accumulation [21, 27]. Moreover, Tariq et al. indicated that hypercholesterolaemic patients $(n=15)$ had an increase in Proteobacteria. After treatment, hypercholesterolaemic patients had an increase in anti-inflammation-associated bacteria such as Akkermansia muciniphila, Faecalibacterium prausnitzii, and Oscillospira [28].

The theory of TCM holds that the pathogenesis of a disease lies in the struggle between Zheng qi (healthy qi) and Xie qi (pathogens). When pathogens hurt the human body, Zheng qi will rise vigorously to expell Xie qi, destroying the relative balance of Yin and Yang. In a previous study, probiotics coordinated metabolism and immunity, preventing pathogenic microorganisms from invading the human body, which resembled Zheng 
qi. To resist pathogens, the human body will mobilize more Zheng qi. This provides a potential mechanism for explaining the increase in some probiotics in patients. Intestinal microflora dysbiosis is the imbalance between probiotics and pathogenetic bacteria, which is very similar to the pathogenesis of a disease in TCM.

\section{Metabolites of GM affect the occurrence of CHD Trimethylamine $\mathrm{N}$-oxide (TMAO) affects the occurrence of $\mathrm{CHD}$ (Fig. 2)}

TMAO is a metabolite produced by choline and other substances dependent on the GM. According to Koeth's research, the human GM metabolizes choline, phosphatidylcholine and L-carnitine to produce trimethylamine (TMA). TMA is further converted into TMAO catalysed by flavin monooxygenase (FMO) in the liver through oxidation $[29,30]$. In addition to assistance in diagnosing and predicting $\mathrm{CHD}$, TMAO also has the properties of causing AS and CHD. In a three-year follow-up study of 4007 patients with CHD, Tang et al. [31] found that elevated TMAO levels made a higher incidence of malignant cardiovascular events. TMAO has a better evaluation effect than traditional prognostic markers for cardiovascular events [32]. A prospective study of urban Chinese adults found that TMAO levels were still positively associated with CHD after adjusting for diet, blood lipids and other risk factors [33]. In an animal study, Apo
E-/ - mice transplanted with the C57BL/6 J strain (high TMAO production) showed elevated AS levels compared with mice treated with the NZW/Lac J strain (low TMAO production) [34].

At present, researchers explain the risk of $\mathrm{CHD}$ caused by TMAO through multiple mechanisms. First, TMAO causes vascular endothelial damage. A study showed that TMAO could activate the mitogen-activated protein kinase (MAPK) and nuclear factor-kappa B (NF-kB) signalling cascades of human aortic endothelial cells. Then, TMAO causes endothelial inflammation by releasing inflammatory cytokines and enhancing the adhesion of leukocytes to vascular endothelial cells [35]. When TMAO was administered to partially ligated the carotid artery in mice, the NLRP3 inflammasome in the intima of the blood vessels increased [36]. Sun et al. [37] suggested that the priming of NLRP3 was mediated through the ROSTXNIP pathway. In the current study, TXNIP is a protein that connects ROS to the NLRP3 inflammasome. Subsequently, the SDHB/ROS pathway induced apoptosis of vascular endothelial cells and promoted AS in Apo E-I- mice [38]. Second, TMAO promotes thrombosis. Direct exposure of platelets to TMAO contributed to $\mathrm{Ca}^{2+}$ release from intracellular stores, which enhanced platelet hyperresponsiveness and promoted thrombosis [39]. Furthermore, TMAO promotes the

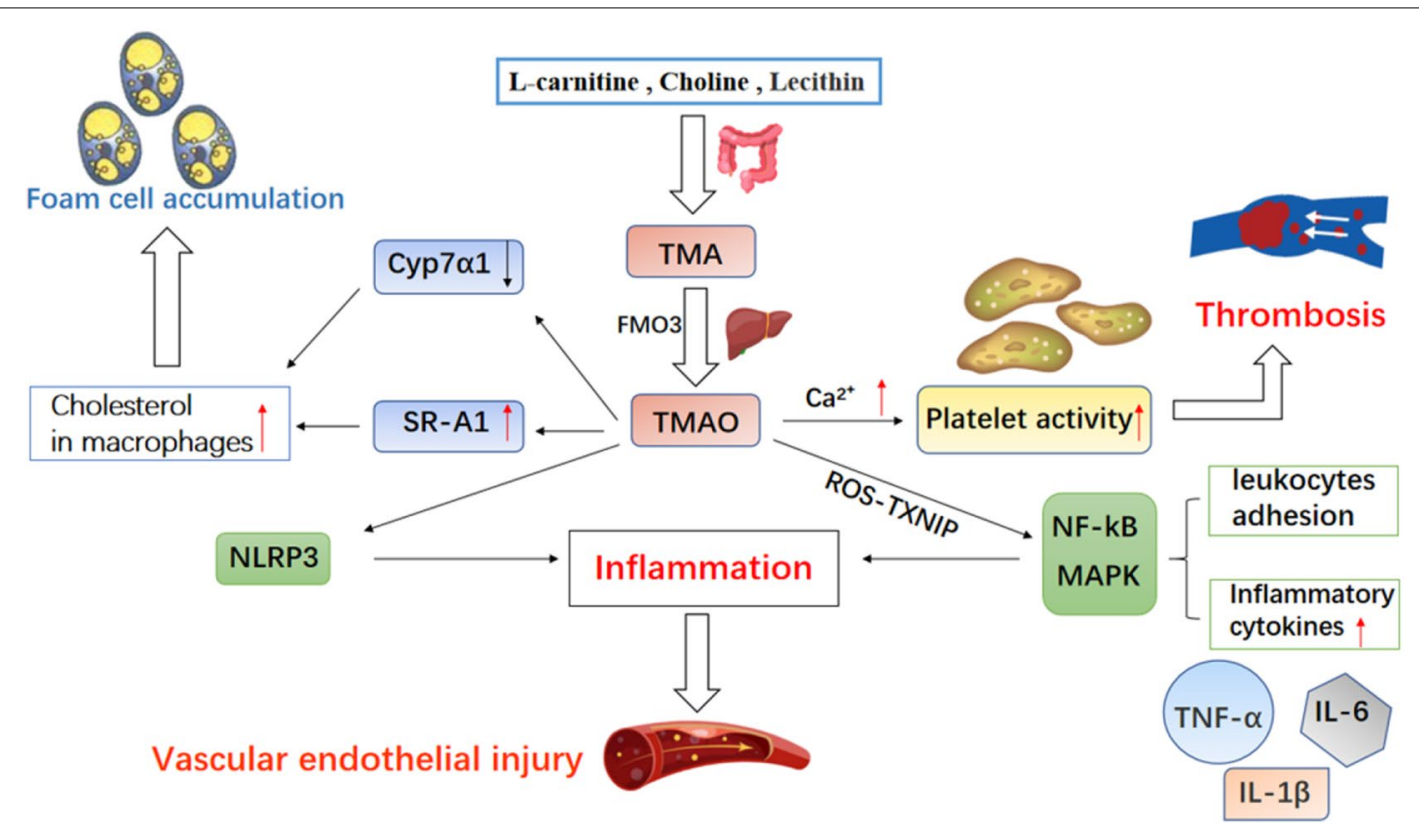

Fig. 2 The mechanism of TMAO affecting CHD. Cyp7al cholesterol 7a-hydroxylase, SR-A1 scavenger receptor A1, NLRP3 pyrin domain-containing-3, TMA trimethylamine, FMO3 flavin-containing monooxygenase 3, TMAO trimethylamine N-oxide, TXNIP thioredoxin binding protein, $R O S$ reactive oxygen species, NF-KB nuclear factor-kappa B, MAPK mitogen-activated protein kinase, TNF- $a$ tumor necrosis factor-a, IL-6 interleukin 6, IL-1 $\beta$ interleukin-1 beta 
deposition of cholesterol in macrophages and the formation of foam cells by upregulating the expression of scavenger receptor A (SRA) [40]. On the other hand, TMAO activated farnesoid X receptor (FXR) and small heterodimer partners to inhibit bile acid synthesis by reducing CYP7A1 expression [41]. This caused cholesterol accumulation and foam cell formation. Then, foam cells accumulate to form lipid streaks and even lipid plaques, which promote AS. This inferred that growing TMAO could accelerate the occurrence of AS. Thus, treatment regimens for CHD that reduce TMAO levels have become a hot spot.

\section{Short-chain fatty acids (SCFAs) affect the occurrence of CHD}

\section{(Fig. 3)}

SCFAs are organic fatty acids with carbon atom numbers less than 6, mainly acetic acid, propionate, and butyrate [42], produced by digestion of resistant starch and dietary fibre in the intestine by different bacteria (Table 1). As a risk factor for CHD, hypertension can be regulated by SCFAs binding to olfaction receptor 78 (OLFR78), G-protein coupled receptor 41 (GPR41), and G-protein coupled receptor 43 (GPR43) [43]. Studies have shown that butyrate reduces cholesterol absorption by downregulating the expression of Niemann-pick C1-Like1 and upregulating the expression of ATP-binding cassette transporters G5 and G8, thereby

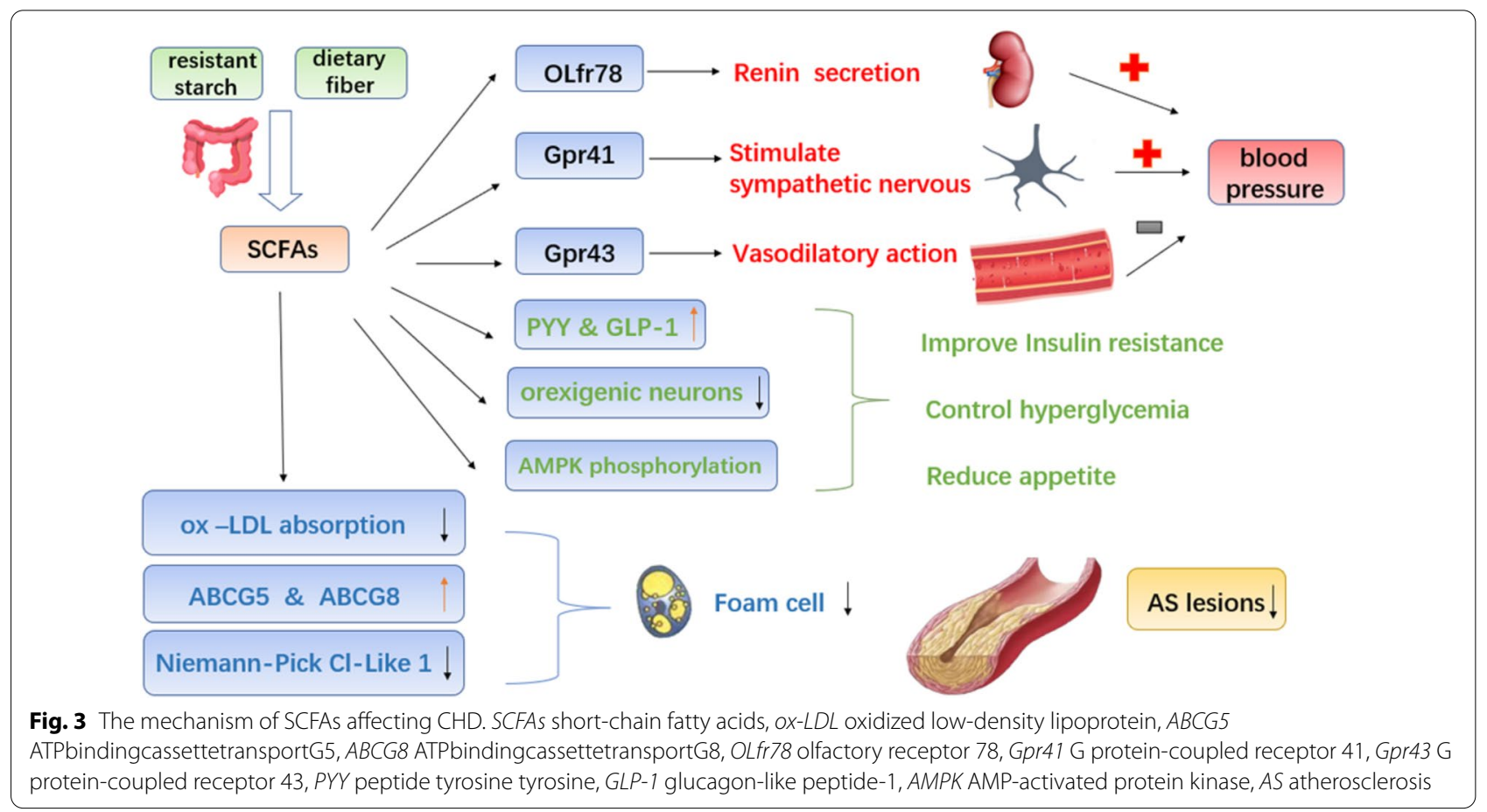

Table 1 SCFAs and their producers

\begin{tabular}{ll}
\hline SCFAs & Producers \\
\hline Butyrate & Eubacterium rectale, Roseburia intestinalis, Clostridium butyricum [50], \\
& Roseburia inulinivorans, Faecalibacterium prausnitzii [51], \\
Coprococcus catus, Eubacterium ballii [52] & Phascolarctobactreium succinatutens, Mycobacterium tuberculosis [51], \\
& E. coli, Bacteroides fragilis B. ruminicola [53], \\
& Salmonella typhimurium [54], \\
& Roseburia inulinivorans [55], \\
& Dalister spp., Veilonella spp., Megasphaera elsdenii, Coprpcoccus catus, Ruminocossus obeum [52] \\
& Most of gut microbiome \\
Acetate & Akkermansia mucinipbilia, Bateroides spp., Bifidobacterium spp., Prevotella spp., Chrostridium \\
& spp., Streptococcus spp. [52], \\
& Roseburia spp., Coprococcus spp., Faecalibacterium prausnitzii, Roseburia intestinalis [56], \\
& Ruminococcus spp., Blautia drogentrophica [57]
\end{tabular}


further reducing the formation of AS [44]. Butyrate also reduced the expression of oxidized low-density lipoprotein (ox-LDL)-stimulated macrophages, which lessened ox-LDL absorption and the formation of foam cells [45]. In an animal study conducted by Bartolomaeus et al. [46], AS lesions were significantly reduced in apolipoprotein $\mathrm{E}$ knockout-deficient mice after receiving propionate. Furthermore, SCFAs could activate adenosine $5^{\prime}$-monophosphate (AMP)-activated protein kinase (AMPK) phosphorylation and glucagon-like peptide-1 (GLP-1) secretion to decrease inflammation and promote insulin resistance [47].Moreover, SCFAs via the gut-brain neural circuit suppressed the activity of orexigenic neurons that expressed neuropeptide $Y$ in the hypothalamus to reduce appetite [48]. Ingestion of propionate significantly increased peptide YY and GLP-1, ultimately reducing food intake and improving insulin sensitivity [49]. It is now recognized that SCFAs are beneficial to reduce the formation of AS, but many experiments are based on cell and animal experiments, so further investigations are needed.

\section{Bile acids (BAs) affect the occurrence of CHD}

BAs are important components of bile and play a fundamental role in fat metabolism [58]. The metabolism of BAs is also connected with plasma glucose [59] and CHD by a 20-year follow-up experiment [60]. Bile salt hydrolase (BSH), which exists in GM, can catalyse the hydrolysis of conjugated bile salts into deconjugated BAs, maintaining the balance of BA metabolism. In a recent study, BSH was shown to be produced by several intestinal bacteria, such as Clostridium [61], Lactobacillus [62], Bifidobacterium [63, 64], Bacteroides [65] and Enterococcus [66]. Song et al. investigated whether there was a prominent discrepancy between healthy people and patients with diabetes and atherosclerosis in terms of BSH [67]. Dysbiosis of the GM caused a reduction in BSH, which significantly impaired the metabolism of BAs and made cholesterol beyond the normal range as well as an inability to maintain glucose homeostasis, promoting the formation of AS [66].

In an animal experiment, Sayin et al. found that GM activated the expression of fibroblast growth factor 15 (FGF15) by reducing tauro-beta-muricholic acid (T $\beta M C A$ ) levels and activating FXR. The expression of FGF15 further inhibited CYP7A1, reducing the generation of BAs [68]. Interventions with probiotics [69] and Tempol [70] could downregulate the FXR/FGF15 pathway to influence the metabolism of fat. Collectively, targeting gut flora to inhibit the FXR/FGF15 pathway could be a treatment for AS.

\section{Mechanism of gut microbiota in the aetiology of TCM for CHD}

Regarded as the foundation of digestion and absorption, the spleen and stomach in TCM theory are similar to the physiological function of the GM. The stomach governs the intake and digestion of the diet, while the spleen is responsible for transforming the decomposed diet into qi, blood and fluid (the material foundation of human activities). Eventually, these materials are transmitted to organs and other tissues by the spleen, offering adequate nourishment. Bacteria in the gut play analogous roles in the digestion and absorption of nutrients converted from food. Thus, it is believed that the GM belongs to the category of spleen and stomach in TCM.

The theory of TCM holds that the pathogenesis of CHD is characterized by phlegm, blood stasis and toxin. An improper diet, lack of rest, severe stress and other pathogenic factors will cause dysfunction of the spleen and stomach, mainly manifesting as qi deficiency. The deficiency of qi indicated that the power to promote fluid flow is insufficient, and stagnant fluid will accumulate to form phlegm. Excessive phlegm can be absorbed into the meridian, leading to blood stasis. The long-term blockade of phlegm and blood stasis in vessels cause the occurrence of heat toxin. Phlegm, blood stasis and toxin obstruct the heart meridian, becoming the pathological mechanism for cardiovascular diseases.

Dysfunction of the spleen and stomach closely resembles gut flora disorder. Blood lipids and TMAO are biomarkers of phlegm and stasis in TCM [71]. TMAO, converted from food by GM, not only causes hyperlipidaemia but also promotes thrombosis. Microbiota dysbiosis and an increase in pathogenic bacteria can be regarded as "external toxins", while microbiota-derived metabolite dysfunction is regarded as an "internal toxin" [72], resulting in hypertension, hyperglycaemia, hyperlipidaemia, inflammation and obesity. This is the similar pathological basis of heart vessel occlusion, explaining the phlegm, blood stasis and toxin in TCM from a modern microbiology perspective. Therefore, TCM treats CHD by promoting blood circulation, removing phlegm and blood stasis, and detoxifying; on the one hand, TCM intervenes in CHD by reducing hypertension, hyperglycaemia, hyperlipidaemia, inflammation and obesity by adjusting the intestinal flora (Fig. 4).

\section{Therapeutic intervention with TCM}

Most herbs are administered orally and absorbed through the intestine. Bacterial enzymes in the intestine are directly involved in the absorption and metabolism of TCM. Several investigations have shown that TCM monomers and compounds might improve the symptoms of CHD and its risk factors by modulating the gut flora [73]. This paper discussed Therapeutic Intervention with TCM according to classification of monomers, single herbs, herb pairs, decoctions.

\section{Monomers (Table 2)}

\section{Resveratrol}

Resveratrol (RSV), a natural polyphenolic compound present in many medicinal herbs (including Polygonum 

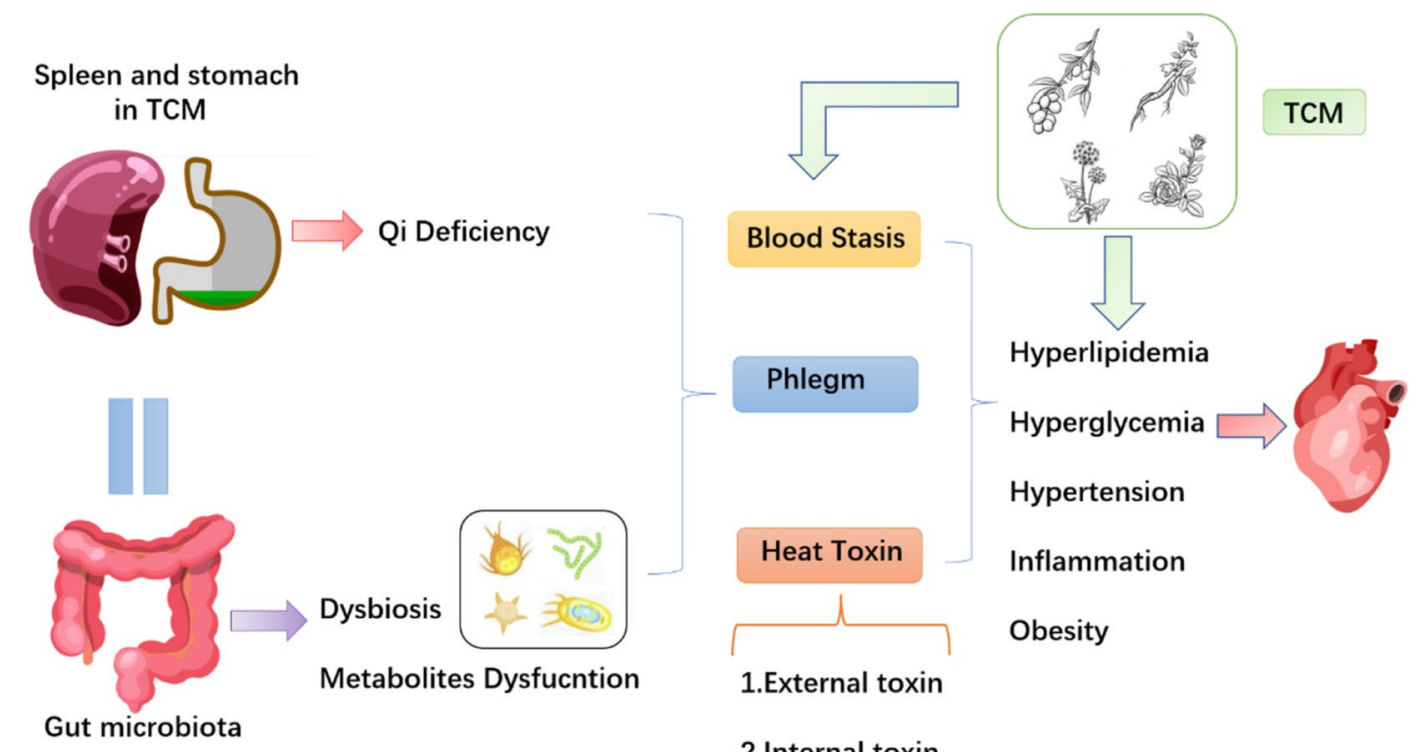

Fig. 4 Gut microbiota linked to spleen and stomach in TCM and coronary heart disease. TCM traditional Chinese medicine

Table 2 Herb monomers and gut microbiota

\begin{tabular}{|c|c|c|c|c|}
\hline Monomers & Herbs & $\begin{array}{l}\text { Physiological function related to } \\
\text { gut microbiota }\end{array}$ & Gut microbiota & References \\
\hline Resveratrol & $\begin{array}{l}\text { Polygonum cuspidatum, Ampelopsis } \\
\text { japonica, Smilax glabra Roxb }\end{array}$ & $\begin{array}{l}\text { (1) Improve the dysbiosis of gut } \\
\text { microbiota } \\
\text { (2) Reduce TMA via inhibiting the } \\
\text { metabolism of choline and attenuate } \\
\text { TMAO-induced AS } \\
\text { (3) Activate the BSH and promote the } \\
\text { catabolism of BAs } \\
\text { (4) Decrease mRNA expression of } \\
\text { genes related to fatty acid synthesis, } \\
\text { lipogenesis and adipogenesis through } \\
\text { the FiaF signaling pathway } \\
\text { (5) Improve glucose homeostasis in } \\
\text { obese individuals } \\
\text { (6) Lower the inflammatory state of } \\
\text { obese individuals }\end{array}$ & $\begin{array}{l}\text { Increased: } \\
\text { the ratio of Bacteroides to Firmi- } \\
\text { cutes, Lactobacillus, Bifidobacterium, } \\
\text { Bacteroides, Parabacteroides } \\
\text { Decreased: } \\
\text { Enterococcus faecalis, } \\
\text { Proteobacteria, } \\
\text { Turicibacteraceae, Moryella, Lachno- } \\
\text { spiraceae, }\end{array}$ & $\begin{array}{l}\text { Chen et al. [74] } \\
\text { Qiao et al. [75] } \\
\text { Sung et al. [76] }\end{array}$ \\
\hline Berberine & $\begin{array}{l}\text { Coptis chinensis Franch, cortex phel- } \\
\text { lodendri }\end{array}$ & $\begin{array}{l}\text { (1) Reduce atherosclerosis } \\
\text { (2) Revert the high-fat diet-induced } \\
\text { structural changes of gut microbiota } \\
\text { and enrich SCFA-producing bacteria } \\
\text { (2) Lower arterial and intestinal expres- } \\
\text { sion of proinflammatory chemokines } \\
\text { and cytokines } \\
\text { (3) Suppress anaerobic production of } \\
\text { TMA and inhibit the choline-to-TMA } \\
\text { transformation } \\
\text { (4) Reduce body weight, blood glu- } \\
\text { cose levels and intestinal inflammation }\end{array}$ & $\begin{array}{l}\text { Increased: } \\
\text { Akkermansia spp., } \\
\text { Allobaculum, Butyricoccus, } \\
\text { Blautia, } \\
\text { Bacteriodes, Phascolarctobacterium, } \\
\text { Ruminococcus, Coprococcu, } \\
\text { Lactobacillus } \\
\text { Decreased: } \\
\text { C. sporogenes, } \\
\text { A. hydrogenalis, } \\
\text { Prevotella, } \\
\text { Proteus }\end{array}$ & $\begin{array}{l}\text { Zhu et al. [77] } \\
\text { Li et al. [78] } \\
\text { Zhang et al. [79] } \\
\text { Zhang et al. [80] }\end{array}$ \\
\hline
\end{tabular}

TMA trimethylamine, TMAO trimethylamine $\mathrm{N}$-oxide, AS atherosclerosis, BSH bile salt hydrolase, BAs bile acids, spp species pluralis, SCFAs short chain fatty acids

Cuspidatum, Ampelopsis japonica and Smilax glabra Roxb), has the clinical effect of improving blood glucose and lipid homeostasis [81], reducing fat mass and blood pressure [82], and alleviating oxidative stress and inflammation [83]. A growing body of evidence supports the hypothesis that RSV plays a role primarily through remodelling the gut microbiota. A study suggested that RSV attenuated TMAO-induced AS by increasing the 
ratio of Bacteroides to Firmicutes $(\mathrm{B} / \mathrm{F})$, thereby reducing TMA by inhibiting the metabolism of choline [74]. In addition, significantly increasing the abundance of Lactobacillus and Bifidobacterium, RSV activated BSH and promoted the catabolism of BAs in the intestine to regulate the synthesis of BAs in the liver [74]. In terms of obesity, RSV improved the dysbiosis of gut microbiota induced by the high-fat diet, including increasing the ratio of $\mathrm{B} / \mathrm{F}$ and the growth of Lactobacillus and Bifidobacterium (negatively correlated with body weight) and inhibiting the growth of Enterococcus faecalis (positively correlated with body weight). The FiaF signalling pathway significantly decreased the mRNA expression of genes related to fatty acid synthesis, lipogenesis and adipogenesis [75]. A group [76] carried out a faecal microbiota transplant (FMT) and showed that decreases in Proteobacteria with resveratrol-FMT were associated with changes in sphingomyelins and phosphatidylcholines. They have been implicated in inflammation and the inflammatory pathway [84], thereby lowering the inflammatory state of obese mice. In addition to the changes in gut microbiota induced by resveratrol, the composition of the gut microbiome regulates the production of resveratrol metabolites (including Piceid [85], dihydroresveratrol and 3,4'-dihydroxy-trans-stilbene [86]), whose concentrations in humans after ingestion are higher than those of their parent molecules and can have similar biological effects.

\section{Berberine}

Berberine (BBR), an isoquinoline alkaloid, can be found in several medicinal herbs, including Coptis chinensis Franch and cortex phellodendri. BBR and BBR-containing herbs have been shown to be effective and safe in antiatherosclerotic [87], antilipidaemic [88], anti-inflammatory [89] and antiobesity [90] applications. Recent studies have shown that the gut microbiota is one of the connections between the poor oral bioavailability of BBR and its pharmacological effects. The gut microbiota converts $B B R$ into its absorbable form of dihydroberberine (dhBBR), whose absorption rate is fivefold higher than that of BBR in animals. DhBBR is unstable in solution and can then be reoxidized to BBR in intestinal tissues [91]. Zhu et al. [77] investigated the association between alterations in the gut microbial structure and the antiatherosclerotic effect of BBR in HFD-fed ApoE-/-mice. BBR treatment increased Akkermansia spp. abundance markedly, contributing to the lower arterial and intestinal expression of proinflammatory chemokines and cytokines as well as the reduction of atherosclerosis. The results by Li et al. [78] from in vitro, ex vivo to in vivo studies proved that BBR could suppress anaerobic production of TMA in both bacterial isolates and the complex gut microbial community, especially showing stronger inhibition of the choline-to-TMA transformation in the detected strains $A$. hydrogenalis and $C$. sporogenes. It may be the main potential mechanism of $\mathrm{BBR}$ in reducing TMA production, ultimate TMAO formation and aortic plaque area. Moreover, BBR showed reverting effects on HFD-induced structural changes in the gut microbiota [79], including the enrichment of SCFA-producing bacteria and a reduction in microbial diversity. Those belonging to putative SCFA-producing bacteria, including Allobaculum, Butyricoccus, Blautia, Bacteroides and Phascolarctobacterium, were significantly increased by BBR to resist obesity-related metabolic disorders. By modifying the gut microbiome, BBR reduced body weight, blood glucose levels and intestinal inflammation in $\mathrm{db} / \mathrm{db}$ mice [80]. Changes in the gut microbiome were characterized by an increased relative abundance of SCFA-producing bacteria (e.g., Ruminococcus, Coprococcu, Butyricimonas) and other probiotics, including Lactobacillus and Akkermansia. A decreased relative abundance of opportunistic pathogens (e.g., Prevotella, Proteus) was also observed.

\section{Herbs (Table 3)}

\section{Mulberry leaf}

Mulberry leaves have been used as traditional medicine, and their traditional effects include dispersing wind and heat, purging heat from the liver and improving eyesight, cooling blood and haemostasis. Its main ingredients, such as mulberry flavonoids, mulberry polysaccharides, mulberry fibre, mulberry polyphenols and mulberry alkaloids, have been reported to play roles in its antihyperglycaemic and antilipidaemic effects by modulating the gut microbiota. Mulberry leaf water extracts (MWEs) could promote SCFA-produced gut microbial fermentation and the excretion of faecal sterol and bile acid, thus helping reduce the serum total cholesterol level and the atherosclerotic index in HFD-fed mice [92]. Similarly, Wang et al. [94] described that mulberry polysaccharides might promote the growth of Bacteroides. In turn, Bacteroides ovatus and Bacteroides cellulosilyticus could degrade mulberry polysaccharides into monosaccharides and oligosaccharide fragments and generate SCFAs that are beneficial to intestinal health. Ma et al. [93] revealed that MWE modified the disturbed gut microbiota to be restored in obese rats (including an increased abundance of Leptotrichia and Bacteroidetes and decreased abundance of Cyanobacteria and Proteobacteria), which may be a mechanism of MWE in improving lipid metabolism and preventing body fat accumulation. In addition, $\mathrm{Li}$ et al. [97] reported the synergistic interaction between mulberry dietary fibre and polyphenols in anti-obesity by 


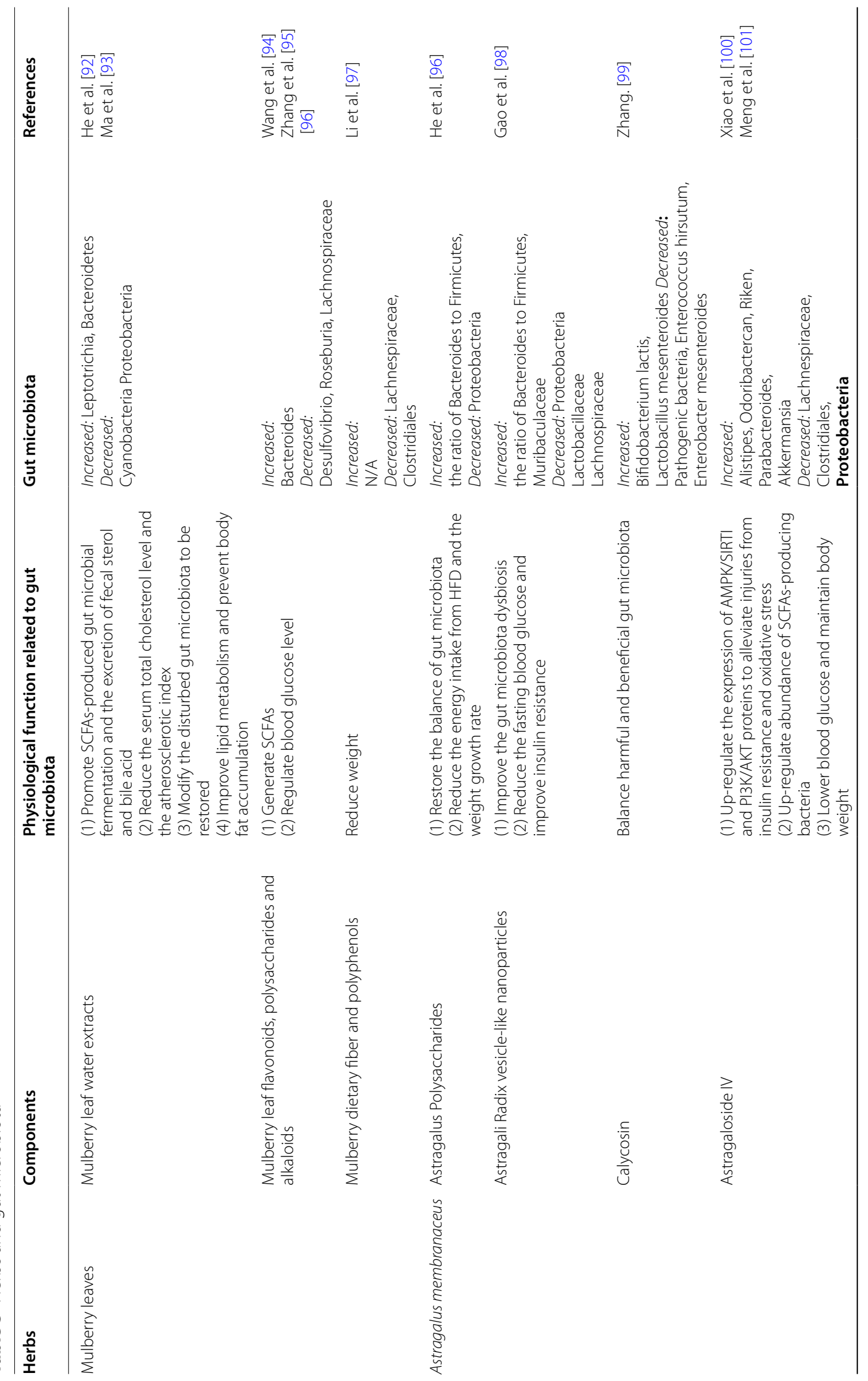




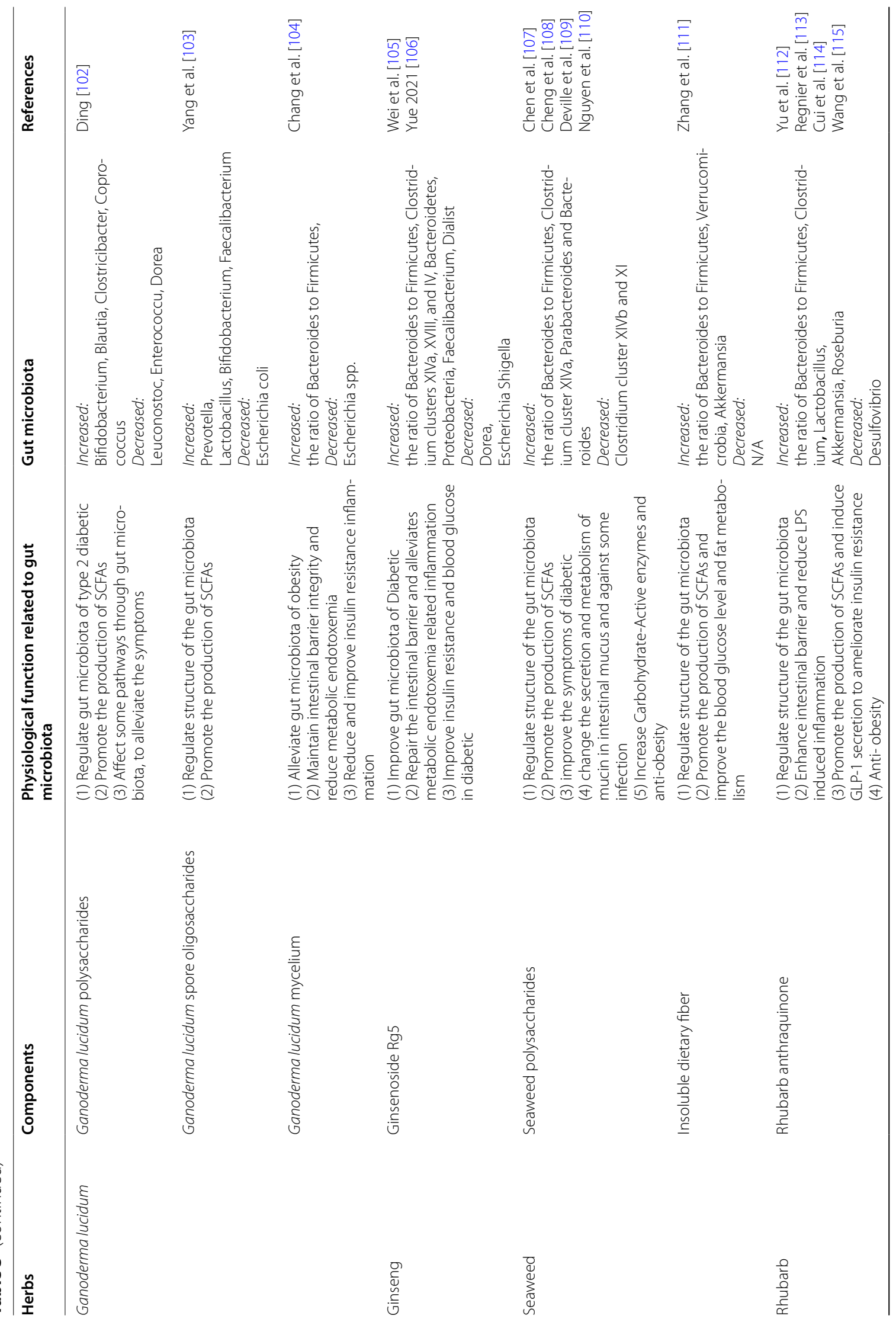




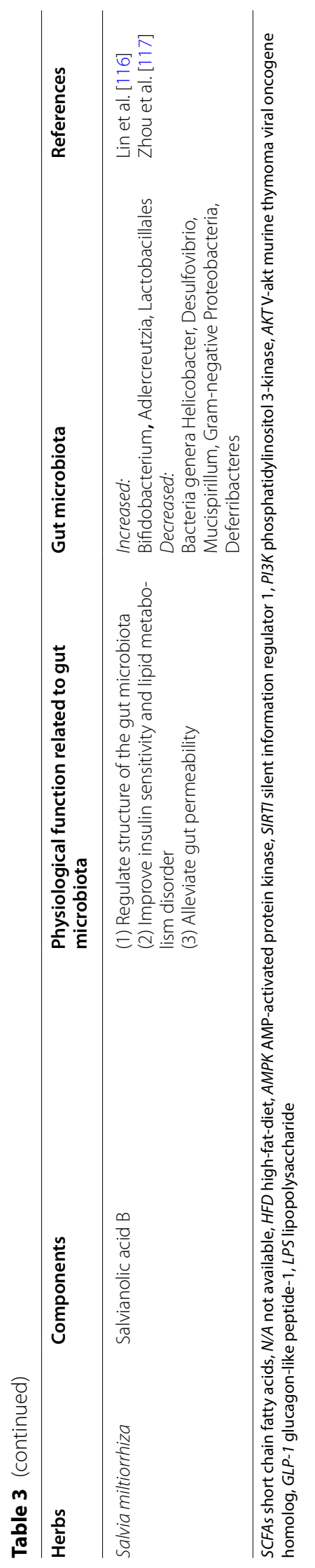


regulating gut microflora for the first time. Their molecular interactions affect the bioavailability and beneficial effects in the food matrix [118]. Mulberry dietary fibre and polyphenols regulate the Firmicutes content to a normal level and reduce the amount of Lachnespiraceae (belonging to Firmicutes/Clostridiales) to achieve weight loss. A group [96] studied the effects of mulberry leaf flavonoids, polysaccharides and alkaloids on gut microflora in $\mathrm{db} / \mathrm{db}$ diabetic mice. After administration, Desulfovibrio, Roseburia, Lachnospiraceae and Bacteroidetes were markedly regulated from disorder, which effectively regulated blood glucose levels, especially in the alkaloid group. This is consistent with the hypoglycaemic mechanism of alkaloids, that is, reducing postprandial hyperglycaemia by inhibiting $\alpha$-glucosidase in the small intestine [119].

\section{Astragalus membranaceus}

Astragalus membranaceus is a commonly used Qi-tonics medicine in the clinical practice of traditional Chinese medicine. Flavonoids, polysaccharides and saponins, the main ingredients of Astragali membranaceus, have functions of regulating immunity, lowering blood glucose and improving cardiac function. In the relevant mechanism of their effectiveness, gut microflora plays an essential role in improving their bioavailability and has impacts on their efficacy [120]. A study in HFD-induced obese mice [96] showed that Astragalus polysaccharides (APS) restored the balance of gut microbiota by increasing the relative abundance of Bacteroidetes and Firmicutes and reducing the abundance of Proteobacteria bacteria. The transplantation of gut microbiota in APS-fed mice could significantly reduce the weight growth rate of HFD-fed mice. This effect of gut microbiota could only be played under the condition of HFD, which showed that the gut microbiota changed by APS reduce the energy intake from HDF. Gao et al. [98] reported that after 3 weeks of administration, compared with the model group, Astragali Radix vesicle-like nanoparticle (VLN) groups could markedly reduce the fasting blood glucose of $\mathrm{db} / \mathrm{db} \mathrm{dia}$ betic mice by improving gut microbiota dysbiosis (an increased relative abundance of beneficial bacteria and the ratio of $\mathrm{B} / \mathrm{F})$. Moreover, calycosin is a flavonoid component of Astragalus. Zhang [99] suggested that calycosin may regulate intestinal health by balancing harmful and beneficial gut microbiota. It inhibited the growth of pathogenic bacteria, Enterococcus hirsutum and Enterobacter mesenteroides in a dose-dependent manner and, at suitable concentrations, promoted the growth of beneficial bacteria such as Bifidobacterium lactis and Lactobacillus mesenteroides. Astragaloside IV (AST) is one of the major active components of astragalosides and has no first pass effect after oral administration [121]. Xiao
[100] demonstrated that AST increased genera such as Alistipes, Odoribactercan, and Riken in $\mathrm{db} / \mathrm{db}$ mice, which could upregulate the expression of AMPK/SIRTI and PI3K/AKT proteins to alleviate injuries from insulin resistance and oxidative stress. Meanwhile, the upregulated abundance of SCFA-producing bacteria, including Blautia, Rikenellaceae, Alistipes, Lachnospiraceae, and Butyrivibrio, was observed. Furthermore, Meng et al. [101] explored the hypoglycaemic mechanism of astragaloside IV combined with berberine (BBR). They reported that the combination of astragaloside IV and BBR was more effective for lowering blood glucose and maintaining body weight than alone in type 2 diabetic rats. In the combined group with a decrease in blood glucose, the abundances of Parabacteroides and Akkermansia were increased, while the abundance of Proteobacteria was reduced.

\section{Ganoderma lucidum}

Ganoderma lucidum is a traditional Chinese medicine made of dried fruiting bodies of fungi that has the function of Tonifying Qi and tranquilizing the mind, stopping cough, and relieving asthma. Recent studies have shown that Ganoderma lucidum has antioxidant, hypoglycaemic, and hypolipidaemic effects and has potential therapeutic effects on AS, whose mechanism is related to gut microbiota. Ding's research shows that [102]. Ganoderma lucidum polysaccharides promote the production of SCFAs through the fermentation of intestinal microflora, such as acetic acid, propionic acid, and butyric acid, which regulate the blood glucose level and impair glucose tolerance in diabetic rats. Meanwhile, Ganoderma lucidum polysaccharide can significantly change the composition and structure of gut microbiota to promote the growth of beneficial bacteria, such as Bifidobacterium, Clostribacteriaceae, Blautia, and Coprocccus, and inhibit the growth of harmful bacteria, such as Dorea and Leuconostoc. It affects the activity of various pathways through gut microbiota, such as bacterial chemotaxis, flagellar assembly, and glycan biosynthesis and metabolism, which can alleviate the symptoms of type 2 diabetic rats. Additionally, Ganoderma lucidum spore oligosaccharides extracted from Ganoderma lucidum spore powder can promote the production of SCFAs and increase the abundance of beneficial bacteria such as Lactobacillus and Prevotella [103]. In addition, Chang [104] and his colleagues found that Ganoderma lucidum mycelium (WEGL) can improve the intestinal barrier to prevent LPS of gram-negative bacteria from entering enterohepatic circulation, activate TLR4 signalling and reduce macrophage infiltration, and enhance Treg accumulation in liver and adipose tissue, which can reduce inflammation in HFD-fed mice. Phosphorylation of serine 307 on 
IRS-1 was inhibited by WEGL in hepatic and adipose tissues to improve insulin resistance. In terms of obesity, WEGL can reduce the F/B ratio and Escherichia spp. in HFD-fed mice and increase a variety of bacterial species negatively related to obesity.

\section{Ginsenoside}

Ginsenoside is the main active component of ginseng, which can not only alleviate the occurrence and development of AS but also improve its risk factors. Ginsenoside $\mathrm{Rb} 1$ can alleviate AS by reducing hyperlipemia [122], inhibiting inflammation [123], and inhibiting calcification of vascular smooth muscle cells (VSMCs) [124]. According to the experimental results of Yange Wei [105], ginsenoside $\operatorname{Rg} 5$ can significantly reduce the ratio of $\mathrm{F} / \mathrm{B}$ and increase Clostridium clusters XIVa, XVIII, and IV in $\mathrm{db} /$ $\mathrm{db}$ mice. Clostridium clusters XIVa, XVIII, and IV have been shown to reduce inflammation by activating Treg cells [125]. Yue's experiment found that protopanaxatriol saponins could increase the abundance of Faecalibacterium and Dialist and reduce the abundance of Dorea and Escherichia Shigella [106]. In addition, Rg5 can improve the expression of occludin and $\mathrm{ZO}-1$ to repair the intestinal barrier. By regulating the composition of the gut microbiota, it also significantly reduces LPS levels and inhibits the TLR4-related inflammatory signalling pathway to alleviate metabolic endotoxaemia-related inflammation. In addition, Rg5 can reverse the JNK pathway and activate NF-kB, which improves insulin resistance and blood glucose in diabetic $\mathrm{db} / \mathrm{db}$ mice [125].

\section{Seaweed}

Seaweed is rich in dietary fibre and divided into soluble dietary fibre and insoluble dietary fibre. According to the American Association of Cereal Chemists (AACC), dietary fibre includes polysaccharides, oligosaccharides, lignin, and associated plant substances that promote beneficial physiological effects, such as the attenuation of blood cholesterol and blood glucose [126]. Recent studies have shown that saccharides in seaweed can effectively treat and prevent coronary atherosclerosis from many aspects [127-129]. Seaweed polysaccharides can reduce the F/B ratio and improve the symptoms of diabetic mice $[107,108]$. In Deville's study [109], seaweed polysaccharide increases SCFAs in the intestine and reduces $\mathrm{pH}$ in the intestine, which is conducive to inhibiting the growth of harmful bacteria. Additionally, it changes the secretion and metabolism of mucin in intestinal mucus to influence the adherence and translocation of gut microbiota across the epithelial wall and against some infections [110]. In anti-obesity diets, seaweed polysaccharide-supplemented diets increase carbohydrate-active enzymes (CAZy), which include an increase in some enzymes associated with a decline in the human body mass index, by increasing bacteria that digest dietary polysaccharides and decreasing potentially pathogenic bacteria. In addition, Zhang's experiment [111] showed that insoluble dietary fibre in seaweed could dose-dependently reduce the number of Firmicutes and increase Verrucomicrobia in HFD mice. At the same time, by adjusting the proportion of akkermansia and a. muciniphila, the SFCA content in the intestine of HFD mice was affected to further improve the blood glucose level and fat metabolism of HFD mice.

\section{Rhubarb}

Rhubarb is one of the most ancient and common herbs in Chinese medicine, and the first record can be traced back to Shen Nong's herbal classic. The main chemical compositions of rhubarb include anthraquinones, anthrones, stilbenes, tannins, polysaccharides, etc. [130]. Traditional Chinese medicine believes that rhubarb has the functions of removing accumulation with purgation, clearing heatfire, clearing heat and toxins from the blood, dredging meridian and relieving blood stasis, promoting diuresis and anti-icteri. Anthraquinone of rhubarb is the main component of rhubarb, which is mainly absorbed in the intestine and has antioxidant [131] and anti-inflammatory [132] functions, regulating lipid metabolism [133]. $\mathrm{Yu}$ and her colleagues [112] found that rhubarb anthraquinone had stronger antibacterial activity against pathogenic bacteria than probiotics through in vitro culture. Rhubarb extract can increase the mRNA expression of REG3 and PLA2g2 in the colon and induce the mRNA expression of intestinal epithelial cell turnover protein in high fat and high sucrose diet rats [113]. Additionally, high-doserhubarb anthraquinone-glycoside treatment can significantly increase the expression of $\mathrm{ZO}-1$ and occludin in type 2 diabetes mellitus rats [114]. These results indicate that rhubarb can enhance intestinal barrier integrity by increasing the expression of specific antimicrobial peptides and major tight junction proteins in the intestine and promoting epithelial cell renewal, which reduces LPS-induced inflammation. In terms of the structure of the gut microbiota, Wang's [115] experiments showed that rhein in rhubarb anthraquinone can increase the $\mathrm{B} / \mathrm{F}$ ratio to reduce obesity and improve glucose metabolism in diabetic mice. In an experiment by Cui et al. [114], both rhubarb anthraquinone-glycoside and metformin reduced pathogenic bacteria such as Desulfovibrio and increased probiotic bacteria (Lactobacillus, actobacillus, and akkermansia). In addition, his study demonstrated that rhubarb anthraquinone-glycoside increases the abundance of some probiotics (Clostridium and Lactobacillus) and SCFA-producing bacteria (akkermansia and Roseburia). These bacteria provide energy 


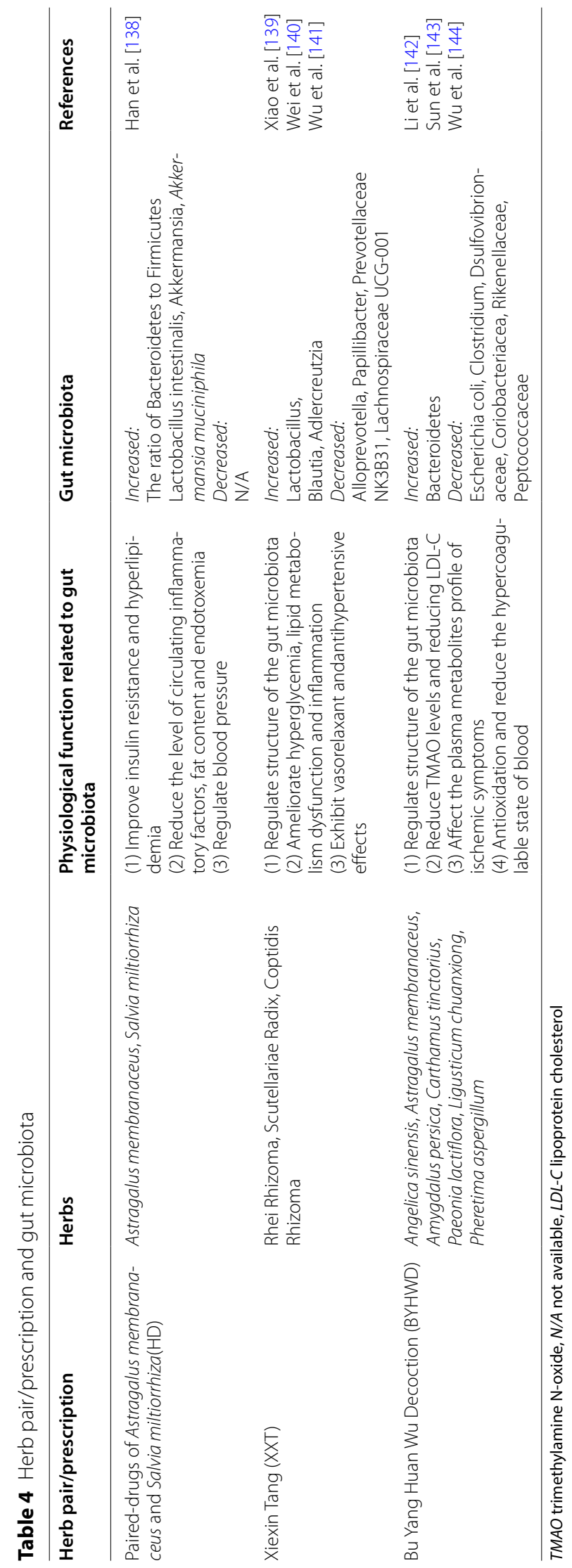


for intestinal L cells to secrete GLP-1 or directly induce GLP-1 secretion to stimulate insulin secretion and improve the sensitivity of peripheral tissue to insulin to ameliorate insulin resistance.

\section{Salvia miltiorrhiza}

Salvia miltiorrhiza is a commonly used drug for promoting blood circulation and removing blood stasis. It is widely used in the treatment of various cardiovascular diseases and has the effects of promoting blood circulation and removing blood stasis, dredging meridians and relieving pain, clearing heart fires and removing annoyance, cooling blood and eliminating carbuncles [134]. Studies have shown that salvianolic acid A in Salvia miltiorrhiza can inhibit the oxidation of LDL, inhibit inflammation, and improve endothelial function to ameliorate AS $[135,136]$. Salvianolic acid B (Sal B) can reverse gram-negative bacteria in HFD mice, which is positively associated with LPS elevation and increases the abundance of adlercreutzia to improve gut permeability [116]. By maintaining intestinal motility, Salvia miltiorrhiza could improve the tolerance of intestinal mucosal epithelial cells to ischaemia and hypoxia to protect intestinal barrier function [117]. Meanwhile, Salvia miltiorrhiza could enhance the barrier function of diabetic mice through the expression of tight junction proteins in the intestine [137]. Thus, Salvia miltiorrhiza can reduce metabolic endotoxaemia by reducing LPS and protecting the intestinal barrier. Furthermore, in Lin's study [116], salvianolic acid B inhibited the LPS/TLR4 signalling pathway by inhibiting the abundance of gram-negative bacteria and improving insulin sensitivity and lipid metabolism disorder in HFD mice.

\section{Herb pair and Decoctions (Table 4)}

\section{Herb pair of Astragalus membranaceus and Salvia miltiorrhiza}

Herb pair, a common form of compatibility in the clinical prescription of TCM, is a pair of two relatively fixed medicines that have a certain theoretical basis and combination rules [145]. Astragalus membranaceus is known as "the best of all drugs for tonifying Qi", and Salvia miltiorrhiza has been proven to. Promote blood circulation and remove blood stasis. Accordingly, the herb pair of Astragalus membranaceus and Salvia miltiorrhiza (HD) is based on the theory of Tonifying Qi and activating blood circulation [146] and has been used to treat CVDs for many years. Han et al. [138] explored the effects and possible mechanism of HD on gut microbiota in spontaneously hypertensive rats (SHRs). In this study, an increased F/B ratio and abundance of Lactobacillus intestinalis, Akkermansia, and Akkermansia muciniphila were observed after administration of HD, which improved insulin resistance and hyperlipidemia and reduced the levels of circulating inflammatory factors, fat content and endotoxemia. Therefore, HD might regulate blood pressure and treat $\mathrm{CHD}$ by regulating related factors.

\section{Xiexin Decoction}

Xiexin Decoction (XXD) is a TCM formula recorded in the masterpiece Synopsis of the Golden Chamber written by ZhongjingZhang. XXD consists of Rhei Rhizoma, Scutellariae Radix, and Coptidis Rhizoma, which has the effect of Clearing heat, detoxifying and drying dampness. Some clinical and animal trials have reproduced the beneficial effects of XXD on AS. XXD effectively regulated lipid metabolism by decreasing triglycerides and LDL and increasing HDL. XXD also downregulated the expression of inflammation-related proteins, such as intercellular adhesion molecule-1 (ICAM-1) and vascular cell adhesion molecule-1 (VCAM-1), playing an anti-inflammatory role. In addition, XXD reduced the apoptosis of vascular endothelial cells induced by ox-LDL, which was related to inhibiting Caspase-9 and Caspase-3 [147]. A recent study showed that intragastric administration of XXD for 4 weeks increased GM-derived SCFA-producing ability by improving key SCFA synthetic enzymes, such as acetate CoA transferase (BUT) and acetate kinase (ACK).The results demonstrated that XXD could effectively ameliorate lipid metabolism disturbance and alleviate inflammation [139]. In a comparitive clinical study, treatment with XXD combined with conventional Western medicine $(n=60)$ significantly reduced blood glucose and blood lipid levels by increasing probiotics [148]. Wei et al. reported that rats treated with XXD exhibited changes in SCFA production and anti-inflammatory bacteria such as Alloprevotella, Adlercreutzia, Barnesiella, and Blautia, ameliorating hyperglycaemia, lipid metabolism dysfunction and inflammation [140]. Furthermore, XXD could increase Lactobacillus abundance, exhibiting vasorelaxant and antihypertensive effects [141].

\section{Bu Yang Huan Wu Decoction}

Bu Yang Huan Wu Decoction (BYHWD) is a classical prescripetion of TCM recorded in the Correction on Errors in Medical Classics, initiated by Qingren Wang, emphasizing the importance of tonifying Qi, promoting blood circulation and removing blood stasis. BYHWD consists of Angelica sinensis, Astragalus membranaceus, Amygdalus persica, Carthamus tinctorius, Paeonia lactiflora, Ligusticum chuanxiong and Pheretima aspergillum. It has been used clinically to treat ischaemic stroke and CHD [149-151]. As a significant risk factor for AS, homocysteine (Hcy) could induce apoptosis of vascular endothelial cells by increasing the production of reactive 
oxygen species (ROS) [152]. However, BYHWD inhibited the NF-kB-dependent pathway to decrease ROS and Hcy, further preventing [153] Meta-analysis also showed that BYHWD was effective in CHD, reducing TC and TG levels [154].

BYHWD treatment $(7.37 \mathrm{~g} / \mathrm{kg} / \mathrm{d})$ for 4 weeks reduced TMAO levels and the abundance of Escherichia coli and Clostridium, reduced LDL-C and ameliorated cardiovascular performance $[142,143]$. It also significantly downregulated Dsulfovibrionaceae, Coriobacteriaceae, Rikenellaceae and Peptococcaceae, which affected the plasma metabolite profile of ischaemic symptoms, mainly threonine, tyrosine, arginine and other amino acid metabolism. In addition, BYHWD upregulated oleamide with antioxidant effects and warfarin to reduce the hypercoagulable state of blood [144]. Therefore, this provides a new provement for improving the ischaemia mechanism of BYHWD.

In accordance with the theory of TCM, the above herbs can be concluded to be qi-invigorating herbs, heat-clearing and detoxicating herbs and blood circulation-promoting and blood stasis-removing herbs. Qi-invigorating herbs not only improve the function of the spleen and stomach but also promote blood circulation in the pulse, which fundamentally solves the generation of pathological products, such as phlegm and blood stasis. Blood circulation-promoting and blood stasis-removing herbs ensure blood vessel unobstructed, preventing stagnation from turning into heat toxin. With a cold nature, heat-clearing and detoxicating herbs reduce the damage of internal and external toxins to the body. These three kinds of drugs are in line with our abovementioned TCM treatment principles for $\mathrm{CHD}$, which can be used by clinicians to choose appropriate drugs to intervene in CHD [155].

In addition, according to the theory of viscera syndrome differentiation, $28.79 \%$ of CHD disease locations are in the spleen and stomach [156]. Most herbal medicines are administered orally and absorbed through the intestine. The GM is directly involved in the absorption and metabolism of TCM. Consequently, GM is closely related to the spleen and stomach. The fact that the abovementioned herbal medicines mostly have channel tropism of the spleen and stomach also confirms this theory. Therefore, the mechanism by which TCM intervenes in CHD by regulating the GM can provide a theoretical basis for TCM "treating coronary heart disease from spleen and stomach", which has clinical guiding value.

\section{Conclusions}

Undoubtedly, there are trillions of bacteria in the human intestine, and the gut microbiota is considered the "second human genome". Currently, an unhealthy lifestyle, abuse of antibiotics and intestinal environment disorders may lead to gut dysbiosis. Previous studies have shown that dysbiosis of the gut microbiota and changes in metabolites, such as TMAO, SCFAs and BAs, are associated with the occurrence and development of coronary heart disease, hypertension, hyperglycaemia, hyperlipidaemia and obesity.

Thus, methods of treating CHD by regulating the GM are emerging. Depending on the multitarget preponderances, TCM can markedly promote probiotic abundance, reduce TMAO, increase SCFAs and supply appropriate BAs to intervene in CHD. These findings extend previous observations and support the nation that TCM may be a new therapeutic target for the prevention and intervention of CHD.

Because $\mathrm{CHD}$ is increasingly appearing among young individuals, the prevention of CHD has become increasingly significant. By understanding the relationship between the patient gut microbiota and CHD treatments, doctors can prevent CHD. Doctors can use TCM to help people who are susceptible to $\mathrm{CHD}$ by regulating the GM. We can also combine a mixed preparation of probiotics with TCM to prevent CHD by promoting the GM, which can eventually reduce the occurrence as well as the societal and economic costs of CHD.

\begin{abstract}
Abbreviations
CHD: Coronary heart disease; GM: Gut microbiota; TCM: Traditional Chinese medicine; TMAO: Trimethylamine N-oxide; SCFAs: Short chain fatty acids; BAs: Bile acids; CNKI: China National Knowledge Infrastructure; CVD: Cardiovascular disease; F/B: Firmicutes/Bacteroidetes; Apo E-/ - mice: Apolipoprotein E knockout (ApoE-/-) mice; AS: Atherosclerosis; ox-LDL: Oxidized low-density lipoprotein; AMPK: AMP activated protein kinase; Spp: Species pluralis; BSH: Bile salt hydrolase; RSV: Resveratrol; B/F: Bacteroidetes/Firmicutes; FMT: Faecal microbiota transplant; BBR: Berberine; HFD: High-fat-diet; db/db mice: Diabetes mice; MWEs: Mulberry leaf water extracts; APS: Astragalus polysaccharides; VLN:Vesicle-like nanoparticle; AST: Astragaloside IV;WEGL: Ganoderma lucidum Mycelium; VSMCs: Vascular smooth muscle cells; AACC: American Association of Cereal Chemists; CAZy: Carbohydrate-active enzymes; Sal B: Salvianolic acid B; N/A: Not available; HD: The herb pair of Astragalus membranaceus and Salvia miltiorrhiza; SHRs: Spontaneously hypertensive rats; XXD: Xiexin Decoction; BYHWD: Bu Yang Huan Wu Decoction; TG: Triglyceride; VLDL: Very low-density lipoprotein; HDL: High-density lipoprotein; LDL: Low-density lipoprotein.
\end{abstract}

\section{Acknowledgements}

Images used in figures were obtained from Scidraw.io.

\section{Authors' contributions}

TYC and JXL wrote and edited this review. PYC, JYC and LRM investigated the information from the references. PYY and GLZ were the administrators of project. All authors read and approved the final manuscript.

\section{Funding}

This work was supported by The Science and Technology Development Fund, Macau SAR (Grant approval No.0011/2021/A).

\section{Availability of data and materials}

Wu, S.C.; Sun, C.Q.; Li, Y.Z.; Wang, T.; Jia, L.H.; Lai, S.Y.; Yang, Y.L.; Luo, P.Y.; Dai, D.; Yang, Y.Q., et al. GMrepo: a database of curated and consistently annotated human gut metagenomes. Nucleic Acids Research 2020, 48, D545-D553, https://doi.org/10.1093/nar/gkz764. 


\section{Declarations}

Ethics approval and consent to participate

Not applicable.

\section{Consent for publication}

Not applicable.

\section{Competing interests}

The authors declare that they have no competing interests.

Received: 29 July 2021 Accepted: 6 October 2021

Published online: 22 October 2021

\section{References}

1. WHO. Cardiovascular diseases (CVDs). World Health Organization, 2021. https://www.who.int/en/news-room/fact-sheets/detail/cardiovasculardiseases-(cvds). Accessed 11 June 2021.

2. Hu ST, Gao RL, Liu LS, Zhu ML, Wang W, Wang YJ, et al. Summary of the 2018 report on cardiovasscular diseases in China. Chin Circ J. 2019;034(003):209-20. https://doi.org/10.3969/j.issn.1000-3614.2019.03. 001.

3. Grundy SM. Consensus statement role of therapy with "Statins" in patients with hypertriglyceridemia. Am J Cardiol. 1998;81(4A):1B-6B. https://doi.org/10.1016/s0002-9149(98)00030-7.

4. Jin K, Khonsari S, Gallagher R, Gallagher P, Clark AM, Freedman B, et al. Telehealth interventions for the secondary prevention of coronary heart disease: a systematic review and meta-analysis. Eur J Cardiovasc Nurs. 2019;18(4):260-71. https://doi.org/10.1177/1474515119826510.

5. Hardin SJ, Singh M, Eyob W, Molnar JC, Homme RP, George AK, et al. Diet-induced chronic syndrome, metabolically transformed trimethylamine-N-oxide, and the cardiovascular functions. Rev Cardiovasc Med. 2019;20(3):121-8. https://doi.org/10.31083/j.rcm.2019.03.518.

6. Qin JJ, Li RQ, Raes J, Arumugam M, Burgdorf KS, Manichanh C, et al. A human gut microbial gene catalogue established by metagenomic sequencing. Nature. 2010;464(7285):59-U70. https://doi.org/10.1038/ nature08821.

7. Hamilton MK, Boudry G, Lemay DG, Raybould HE. Changes in intestinal barrier function and gut microbiota in high-fat diet-fed rats are dynamic and region dependent. Am J Physiol Gastrointest Liver Physiol. 2015;308(10):G840-51. https://doi.org/10.1152/ajpgi.00029.2015.

8. Morrison DJ, Preston T. Formation of short chain fatty acids by the gut microbiota and their impact on human metabolism. Gut Microbes. 2016;7(3):189-200. https://doi.org/10.1080/19490976.2015.1134082.

9. Wu SC, Sun CQ, Li YZ, Wang T, Jia LH, Lai SY, et al. GMrepo: a database of curated and consistently annotated human gut metagenomes. Nucleic Acids Res. 2020;48(D1):D545-53. https://doi.org/10.1093/nar/gkz764.

10. Jie Z, Xia H, Zhong SL, Feng Q, Li S, Liang S, et al. The gut microbiome in atherosclerotic cardiovascular disease. Nat Commun. 2017;8(1):845. https://doi.org/10.1038/s41467-017-00900-1.

11. Cui $L$, Zhao T, Hu H, Zhang W, Hua X. Association study of gut flora in coronary heart disease through high-throughput sequencing. BioMed Res Int. 2017;2017:3796359. https://doi.org/10.1155/2017/3796359.

12. Emoto T, Yamashita T, Sasaki N, Hirota Y, Hayashi T, So A, et al. Analysis of gut microbiota in coronary artery disease patients: a possible link between gut microbiota and coronary artery disease. J Atheroscler Thromb. 2016;23(8):908-21. https://doi.org/10.5551/jat.32672.

13. Emoto T, Yamashita T, Kobayashi T, Sasaki N, Hirota Y, Hayashi T, et al. Characterization of gut microbiota profiles in coronary artery disease patients using data mining analysis of terminal restriction fragment length polymorphism: gut microbiota could be a diagnostic marker of coronary artery disease. Heart Vessels. 2017;32(1):39-46. https://doi.org/ 10.1007/s00380-016-0841-y.

14. Mariat D, Firmesse $O$, Levenez F, Guimaraes VD, Sokol H, Dore J, et al. The Firmicutes/Bacteroidetes ratio of the human microbiota changes with age. BMC Microbiol. 2009;9:6. https://doi.org/10.1186/1471-2180-9-123.

15. Xu J, Bjursell MK, Himrod J, Deng S, Carmichael LK, Chiang HC, et al. A genomic view of the human-Bacteroides thetaiotaomicron symbiosis.
Science (New York, NY). 2003;299(5615):2074-6. https://doi.org/10. $1126 /$ science. 1080029.

16. Liao WH, Henneberg M, Langhans W. Immunity-based evolutionary interpretation of diet-induced thermogenesis. Cell Metab. 2016;23(6):971-9. https://doi.org/10.1016/j.cmet.2016.05.002.

17. Turnbaugh PJ, Ley RE, Mahowald MA, Magrini V, Mardis ER, Gordon Jl. An obesity-associated gut microbiome with increased capacity for energy harvest. Nature. 2006;444(7122):1027-31. https://doi.org/10. 1038/nature05414.

18. Rom O, Korach-Rechtman H, Hayek T, Danin-Poleg Y, Bar H, Kashi Y, et al. Acrolein increases macrophage atherogenicity in association with gut microbiota remodeling in atherosclerotic mice: protective role for the polyphenol-rich pomegranate juice. Arch Toxicol. 2017;91(4):1709-25. https://doi.org/10.1007/s00204-016-1859-8.

19. Poppleton DI, Duchateau M, Hourdel V, Matondo M, Flechsler J, Klingl A, et al. Outer membrane proteome of Veillonella parvula: a Diderm Firmicute of the human microbiome. Front Microbiol. 2017;8:1215. https:// doi.org/10.3389/fmicb.2017.01215.

20. Dong $Y$, Cheng $H$, Liu Y, Xue $M$, Liang $H$. Red yeast rice ameliorates highfat diet-induced atherosclerosis in Apoe(-/-) mice in association with improved inflammation and altered gut microbiota composition. Food Funct. 2019;10(7):3880-9. https://doi.org/10.1039/c9fo00583h.

21. Gomes AC, Hoffmann C, Mota JF. The human gut microbiota: metabolism and perspective in obesity. Gut Microbes. 2018;9(4):308-25. https://doi.org/10.1080/19490976.2018.1465157.

22. Li R, Yang J, Saffari A, Jacobs J, Baek Kl, Hough G, et al. Ambient ultrafine particle ingestion alters gut microbiota in association with increased atherogenic lipid metabolites. Sci Rep. 2017;7:42906. https://doi.org/10. 1038/srep42906.

23. Nie J, Zhang L, Zhao G, Du X. Quercetin reduces atherosclerotic lesions by altering the gut microbiota and reducing atherogenic lipid metabolites. J Appl Microbiol. 2019;127(6):1824-34. https://doi.org/10.1111/ jam.14441.

24. Awdeh ZL, Yunis EJ, Audeh MJ, Fici D, Pugliese A, Larsen CE, et al. A genetic explanation for the rising incidence of type 1 diabetes, a polygenic disease. J Autoimmun. 2006;27(3):174-81. https://doi.org/10. 1016/j.jaut.2006.08.004

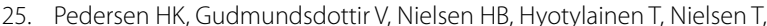
Jensen $\mathrm{BAH}$, et al. Human gut microbes impact host serum metabolome and insulin sensitivity. Nature. 2016;535(7612):376. https://doi.org/ 10.1038/nature18646.

26. Rath S, Heidrich B, Pieper DH, Vital M. Uncovering the trimethylamineproducing bacteria of the human gut microbiota. Microbiome. 2017;5(1):54. https://doi.org/10.1186/s40168-017-0271-9.

27. Pallister T, Jackson MA, Martin TC, Glastonbury CA, Jennings A, Beaumont $M$, et al. Untangling the relationship between diet and visceral fat mass through blood metabolomics and gut microbiome profiling. Int J Obes (2005). 2017;41(7):1106-13. https://doi.org/10.1038/ijo.2017.70.

28. Khan TJ, Ahmed YM, Zamzami MA, Siddiqui AM, Khan I, Baothman $\mathrm{OAS}$, et al. Atorvastatin treatment modulates the gut microbiota of the hypercholesterolemic patients. OMICS. 2018;22(2):154-63. https://doi. org/10.1089/omi.2017.0130.

29. Koeth RA, Wang ZE, Levison BS, Buffa JA, Org E, Sheehy BT, et al. Intestinal microbiota metabolism of L-carnitine, a nutrient in red meat, promotes atherosclerosis. Nat Med. 2013;19(5):576-85. https://doi.org/ 10.1038/nm.3145.

30. Shih DM, Zhu W, Schugar RC, Meng Y, Jia X, Miikeda A, et al. Genetic deficiency of flavin-containing monooxygenase 3 (Fmo3) protects against thrombosis but has only a minor effect on plasma lipid levelsbrief report. Arterioscler Thromb Vasc Biol. 2019;39(6):1045-54. https:// doi.org/10.1161/atvbaha.119.312592.

31. Tang WHW, Wang ZE, Levison BS, Koeth RA, Britt EB, Fu XM, et al. Intestinal microbial metabolism of phosphatidylcholine and cardiovascular risk. N Engl J Med. 2013;368(17):1575-84. https://doi.org/10.1056/ NEJMoa1109400

32. Li XSM, Obeid S, Klingenberg R, Gencer B, Mach F, Raber L, et al. Gut microbiota-dependent trimethylamine $\mathrm{N}$-oxide in acute coronary syndromes: a prognostic marker for incident cardiovascular events beyond traditional risk factors. Eur Heart J. 2017;38(11):814-24. https://doi.org/ 10.1093/eurheartj/ehw582. 
33. Yu DX, Shu XO, Rivera ES, Zhang XL, Cai QY, Calcutt MW, et al. Urinary levels of trimethylamine-N-oxide and Incident coronary heart disease: a prospective investigation among urban chinese adults. J Am Heart Assoc. 2019;8(1):14. https://doi.org/10.1161/jaha.118.010606.

34. Gregory JC, Buffa JA, Org E, Wang Z, Levison BS, Zhu W, et al. Transmission of atherosclerosis susceptibility with gut microbial transplantation. J Biol Chem. 2015;290(9):5647-60. https://doi.org/10.1074/jbc.M114. 618249.

35. Seldin MM, Meng YH, Qi HX, Zhu WF, Wang ZE, Hazen SL, et al. Trimethylamine $\mathrm{N}$-oxide promotes vascular inflammation through signaling of mitogen-activated protein kinase and nuclear factor-kappa B. J Am Heart Assoc. 2016. https://doi.org/10.1161/jaha.115.002767.

36. Boini KM, Hussain T, Li PL, Koka S. Trimethylamine-N-oxide instigates NLRP3 inflammasome activation and endothelial dysfunction. Cell Physiol Biochem. 2017;44(1):152-62. https://doi.org/10.1159/00048 4623.

37. Sun XL, Jiao XF, Ma YR, Liu Y, Zhang L, He YZ, et al. Trimethylamine $\mathrm{N}$-oxide induces inflammation and endothelial dysfunction in human umbilical vein endothelial cells via activating ROS-TXNIP-NLRP3 inflammasome. Biochem Biophys Res Commun. 2016;481(1-2):63-70. https:// doi.org/10.1016/j.bbrc.2016.11.017.

38. Wu P, Chen JN, Chen JJ, Tao J, Wu SY, Xu GS, et al. Trimethylamine $\mathrm{N}$-oxide promotes apoE(-/-) mice atherosclerosis by inducing vascular endothelial cell pyroptosis via the SDHB/ROS pathway. J Cell Physiol. 2020;235(10):6582-91. https://doi.org/10.1002/jcp.29518.

39. Zhu WF, Gregory JC, Org E, Buffa JA, Gupta N, Wang ZN, et al. Gut microbial metabolite TMAO enhances platelet hyperreactivity and thrombosis risk. Cell. 2016;165(1):111-24. https://doi.org/10.1016/j.cell. 2016.02.011.

40. Spector R. New insight into the dietary cause of atherosclerosis: implications for pharmacology. J Pharmacol Exp Ther. 2016;358(1):103-8. https://doi.org/10.1124/jpet.116.233296.

41. Ding L, Chang MR, Guo Y, Zhang LY, Xue CH, Yanagita T, et al. Trimethylamine-N-oxide (TMAO)-induced atherosclerosis is associated with bile acid metabolism. Lipids Health Dis. 2018. https://doi.org/10.1186/ s12944-018-0939-6.

42. de la Cuesta-Zuluaga J, Mueller NT, Alvarez-Quintero R, Velasquez-Mejia EP, Sierra JA, Corrales-Agudelo V, et al. Higher fecal short-chain fatty acid levels are associated with gut microbiome dysbiosis, obesity, hypertension and cardiometabolic disease risk factors. Nutrients. 2019. https:// doi.org/10.3390/nu11010051.

43. Pluznick JL. A novel SCFA receptor, the microbiota, and blood pressure regulation. Gut Microbes. 2014;5(2):202-7. https://doi.org/10.4161/ gmic.27492

44. Chen Y, Xu CF, Huang R, Song JY, Li D, Xia M. Butyrate from pectin fermentation inhibits intestinal cholesterol absorption and attenuates atherosclerosis in apolipoprotein E-deficient mice. J Nutr Biochem. 2018:56:175-82. https://doi.org/10.1016/j.jnutbio.2018.02.011.

45. Aguilar EC, Leonel AJ, Teixeira LG, Silva AR, Silva JF, Pelaez JMN, et al. Butyrate impairs atherogenesis by reducing plaque inflammation and vulnerability and decreasing NF kappa B activation. Nutr Metab Cardiovasc Dis. 2014;24(6):606-13. https://doi.org/10.1016/j.numecd.2014.01. 002.

46. Bartolomaeus H, Balogh A, Yakoub M, Homann S, Marko L, Hoges S, et al. Short-chain fatty acid propionate protects from hypertensive cardiovascular damage. Circulation. 2019;139(11):1407-21. https://doi. org/10.1161/circulationaha.118.036652.

47. Gonzalez A, Krieg R, Massey HD, Carl D, Ghosh S, Gehr TWB, et al. Sodium butyrate ameliorates insulin resistance and renal failure in CKD rats by modulating intestinal permeability and mucin expression. Nephrol Dial Transplant. 2019;34(5):783-94. https://doi.org/10.1093/ ndt/gfy238.

48. Li Z, Yi CX, Katiraei S, Kooijman S, Zhou E, Chung CK, et al. Butyrate reduces appetite and activates brown adipose tissue via the gut-brain neural circuit. Gut. 2018;67(7):1269-79. https://doi.org/10.1136/ gutjnl-2017-314050.

49. Chambers ES, Viardot A, Psichas A, Morrison DJ, Murphy KG, Zac-Varghese SE, et al. Effects of targeted delivery of propionate to the human colon on appetite regulation, body weight maintenance and adiposity in overweight adults. Gut. 2015;64(11):1744-54. https://doi.org/10. 1136/gutjnl-2014-307913.
50. Sanna S, van Zuydam NR, Mahajan A, Kurilshikov A, Vila AV, Vosa U, et al. Causal relationships among the gut microbiome, short-chain fatty acids and metabolic diseases. Nat Genet. 2019;51(4):600. https://doi.org/10. 1038/s41588-019-0350-X.

51. Maji A, Misra R, Dhakan DB, Gupta V, Mahato NK, Saxena R, et al. Gut microbiome contributes to impairment of immunity in pulmonary tuberculosis patients by alteration of butyrate and propionate producers. Environ Microbiol. 2018;20(1):402-19. https://doi.org/10.1111/14622920.14015.

52. Louis P, Hold GL, Flint HJ. The gut microbiota, bacterial metabolites and colorectal cancer. Nat Rev Microbiol. 2014;12(10):661-72. https://doi. org/10.1038/nrmicro3344.

53. Gonzalez-Garcia RA, McCubbin T, Navone L, Stowers C, Nielsen LK, Marcellin E. Microbial propionic acid production. Fermentation Basel. 2017. https://doi.org/10.3390/fermentation3020021.

54. Staib L, Fuchs TM. Regulation of fucose and 1,2-propanediol utilization by Salmonella enterica serovar Typhimurium. Front Microbiol. 2015. https://doi.org/10.3389/fmicb.2015.01116.

55. Scott KP, Martin JC, Campbell G, Mayer C-D, Flint HJ. Whole-genome transcription profiling reveals genes up-regulated by growth on fucose in the human gut bacterium Roseburia inulinivorans. J Bacteriol. 2006;188(12):4340-9. https://doi.org/10.1128/jb.00137-06.

56. Duncan SH, Barcenilla A, Stewart CS, Pryde SE, Flint HJ. Acetate utilization and butyryl coenzyme A (CoA): acetate-CoA transferase in butyrate-producing bacteria from the human large intestine. Appl Environ Microbiol. 2002;68(10):5186-90. https://doi.org/10.1128/aem. 68.10.5186-5190.2002.

57. Rey FE, Faith JJ, Bain J, Muehlbauer MJ, Stevens RD, Newgard CB, et al. Dissecting the in vivo metabolic potential of two human gut acetogens. J Biol Chem. 2010;285(29):22082-90. https://doi.org/10.1074/jbc. M110.117713.

58. Joyce SA, MacSharry J, Casey PG, Kinsella M, Murphy EF, Shanahan F, et al. Regulation of host weight gain and lipid metabolism by bacterial bile acid modification in the gut. Proc Natl Acad Sci U S A. 2014;111(20):7421-6. https://doi.org/10.1073/pnas.1323599111.

59. Cariou B, Chetiveaux M, Zair Y, Pouteau E, Disse E, Guyomarc'h-Delasalle $B$, et al. Fasting plasma chenodeoxycholic acid and cholic acid concentrations are inversely correlated with insulin sensitivity in adults. Nutr Metab. 2011. https://doi.org/10.1186/1743-7075-8-48.

60. Charach G, Argov O, Geiger K, Charach L, Rogowski O, Grosskopf I. Diminished bile acids excretion is a risk factor for coronary artery disease: 20-year follow up and long-term outcome. Ther Adv Gastroenterol. 2017;11:1-11. https://doi.org/10.1177/1756283×17743420.

61. Coleman JP, Hudson LL. Cloning and characterization of a conjugated bile-acid hyrdrolase gene from clostridium-perfringens. Appl Environ Microbiol. 1995;61(7):2514-20. https://doi.org/10.1128/aem.61.7.25142520.1995.

62. Wang Z, Zeng XM, Mo YM, Smith K, Guo YM, Lin J. Identification and characterization of a bile salt hydrolase from Lactobacillus salivarius for development of novel alternatives to antibiotic growth promoters. Appl Environ Microbiol. 2012;78(24):8795-802. https://doi.org/10.1128/ aem.02519-12.

63. Shuhaimi M, Ali AM, Saleh NM, Yazid AM. Cloning and sequence analysis of bile salt hydrolase (bsh) gene from Bifidobacterium longum. Biotechnol Lett. 2001;23(21):1775-80. https://doi.org/10.1023/a:10124 00518207.

64. Kim GB, Miyamoto CM, Meighen EA, Lee BH. Cloning and characterization of the bile salt hydrolase genes (bsh) from Bifidobacterium bifidum strains. Appl Environ Microbiol. 2004;70(9):5603-12. https://doi.org/10. 1128/aem.70.9.5603-5612.2004.

65. Stellwag EJ, Hylemon PB. Purification and characterization of bile-salt hydrolase from Bacteroides-fragilis subsp. fragilis. Biochem Biophys Acta. 1976;452(1):165-76. https://doi.org/10.1016/0005-2744(76) 90068-1.

66. De Filippo C, Cavalieri D, Di Paola M, Ramazzotti M, Poullet JB, Massart S, et al. Impact of diet in shaping gut microbiota revealed by a comparative study in children from Europe and rural Africa. Proc Natl Acad Sci U S A. 2010;107(33):14691-6. https://doi.org/10.1073/pnas.1005963107.

67. Song ZW, Cai YY, Lao XZ, Wang X, Lin XX, Cui YY, et al. Taxonomic profiling and populational patterns of bacterial bile salt hydrolase (BSH) 
genes based on worldwide human gut microbiome. Microbiome. 2019. https://doi.org/10.1186/s40168-019-0628-3.

68. Sayin SI, Wahlström A, Felin J, Jäntti S, Marschall HU, Bamberg K, et al. Gut microbiota regulates bile acid metabolism by reducing the levels of tauro-beta-muricholic acid, a naturally occurring FXR antagonist. Cell Metab. 2013;17(2):225-35. https://doi.org/10.1016/j.cmet.2013.01.003.

69. Degirolamo C, Rainaldi S, Bovenga F, Murzilli S, Moschetta A. Microbiota modification with probiotics induces hepatic bile acid synthesis via downregulation of the Fxr-Fgf15 axis in mice. Cell Rep. 2014;7(1):12-8. https://doi.org/10.1016/j.celrep.2014.02.032.

70. Li F, Jiang C, Krausz KW, Li Y, Albert I, Hao H, et al. Microbiome remodelling leads to inhibition of intestinal farnesoid $X$ receptor signalling and decreased obesity. Nat Commun. 2013;4:2384. https://doi.org/10.1038/ ncomms3384.

71. Ou Y, Zhang C, Yao M, Wang L. Gut Flora: novel therapeutic target of Chinese medicine for the treatment of cardiovascular diseases. Evid Based Complement Altern Med eCAM. 2019;2019:3719596. https://doi. org/10.1155/2019/3719596.

72. Wang AL, Xu H, Chen KY. Exploration on theory of stasis toxic in coronary heart disease from gut microbiota and its metabolite. Chin J Integr Tradit West Med. 2020;40(04):490-2. https://doi.org/10.7661/J.Cjim. 20200113.093.

73. Li ZY, Chen MS. Natural medicines reduce the risk of atherosclerosis via remodeling of gut microbiota: research progress. Chin J Microecol. 2017;29(08):975-9. https://doi.org/10.13381/j.carolcarrollnki.CJM.20170 8027.

74. Chen ML, Yi L, Zhang Y, Zhou X, Ran L, Yang J, et al. Resveratrol attenuates trimethylamine-N-oxide (TMAO)-induced atherosclerosis by regulating TMAO synthesis and bile acid metabolism via remodeling of the gut microbiota. MBio. 2016;7(2):e02210-02215. https://doi.org/10. 1128/mBio.02210-15.

75. Qiao Y, Sun J, Xia S, Tang X, Shi Y, Le G. Effects of resveratrol on gut microbiota and fat storage in a mouse model with high-fat-induced obesity. Food Funct. 2014;5(6):1241-9. https://doi.org/10.1039/c3fo6 0630a.

76. Sung MM, Kim TT, Denou E, Soltys CM, Hamza SM, Byrne NJ, et al. Improved glucose homeostasis in obese mice treated with resveratrol is associated with alterations in the gut microbiome. Diabetes. 2017;66(2):418-25. https://doi.org/10.2337/db16-0680.

77. Zhu L, Zhang D, Zhu H, Zhu J, Weng S, Dong L, et al. Berberine treatment increases Akkermansia in the gut and improves highfat diet-induced atherosclerosis in Apoe(-/-) mice. Atherosclerosis. 2018;268:117-26. https://doi.org/10.1016/j.atherosclerosis.2017.11.023.

78. Li X, Su C, Jiang Z, Yang Y, Zhang Y, Yang M, et al. Berberine attenuates choline-induced atherosclerosis by inhibiting trimethylamine and trimethylamine-N-oxide production via manipulating the gut microbiome. NPJ Biofilms Microbiomes. 2021;7(1):36. https://doi.org/10.1038/ s41522-021-00205-8.

79. Zhang X, Zhao Y, Xu J, Xue Z, Zhang M, Pang X, et al. Modulation of gut microbiota by berberine and metformin during the treatment of highfat diet-induced obesity in rats. Sci Rep. 2015;5:14405. https://doi.org/ 10.1038/srep14405.

80. Zhang W, Xu JH, YuT, Chen QK. Effects of berberine and metformin on intestinal inflammation and gut microbiome composition in $\mathrm{db} /$ db mice. Biomed Pharmacother. 2019;118: 109131. https://doi.org/10. 1016/j.biopha.2019.109131.

81. Chaplin A, Carpéné C, Mercader J. Resveratrol, metabolic syndrome, and gut microbiota. Nutrients. 2018. https://doi.org/10.3390/nu101 11651.

82. Man AWC, Li H, Xia N. Resveratrol and the interaction between gut microbiota and arterial remodelling. Nutrients. 2020. https://doi.org/10. 3390/nu12010119.

83. Breuss JM, Atanasov AG, Uhrin P. Resveratrol and its effects on the vascular system. Int J Mol Sci. 2019. https://doi.org/10.3390/ijms200715 23.

84. Treede I, Braun A, Sparla R, Kühnel M, Giese T, Turner JR, et al. Anti-inflammatory effects of phosphatidylcholine. J Biol Chem. 2007;282(37):27155-64. https://doi.org/10.1074/jbc.M704408200.

85. Wang HL, Gao JP, Han YL, Xu X, Wu R, Gao Y, et al. Comparative studies of polydatin and resveratrol on mutual transformation and antioxidative effect in vivo. Phytomed Int J Phytother Phytopharmacol. 2015;22(5):553-9. https://doi.org/10.1016/j.phymed.2015.03.014.

86. Bode LM, Bunzel D, Huch M, Cho GS, Ruhland D, Bunzel M, et al. In vivo and in vitro metabolism of trans-resveratrol by human gut microbiota. Am J Clin Nutr. 2013;97(2):295-309. https://doi.org/10.3945/ajcn.112. 049379.

87. Tan W, Wang Y, Wang K, Wang S, Liu J, Qin X, et al. Improvement of endothelial dysfunction of berberine in atherosclerotic mice and mechanism exploring through TMT-based proteomics. Oxid Med Cell Longev. 2020;2020:8683404. https://doi.org/10.1155/2020/8683404.

88. Liu C, Wang Z, Song Y, Wu D, Zheng X, Li P, et al. Effects of berberine on amelioration of hyperglycemia and oxidative stress in high glucose and high fat diet-induced diabetic hamsters in vivo. BioMed Res Int. 2015;2015: 313808. https://doi.org/10.1155/2015/313808.

89. Ehteshamfar SM, Akhbari M, Afshari JT, Seyedi M, Nikfar B, ShapouriMoghaddam A, et al. Anti-inflammatory and immune-modulatory impacts of berberine on activation of autoreactive $T$ cells in autoimmune inflammation. J Cell Mol Med. 2020;24(23):13573-88. https://doi. org/10.1111/jcmm.16049.

90. Xu JH, Liu XZ, Pan W, Zou DJ. Berberine protects against diet-induced obesity through regulating metabolic endotoxemia and gut hormone levels. Mol Med Rep. 2017;15(5):2765-87. https://doi.org/10.3892/mmr. 2017.6321.

91. Feng R, Shou JW, Zhao ZX, He CY, Ma C, Huang M, et al. Transforming berberine into its intestine-absorbable form by the gut microbiota. Sci Rep. 2015;5:12155. https://doi.org/10.1038/srep12155.

92. Yan X, Zou LF, Huang XZ, Ding XW. Effects of mulberry leaves water extract on cholesterol metabolites in feces of high-fat diet fed mice. Mod Food Sci Technol. 2019;35(05):37-45+295. https://doi.org/10. 13982/j.mfst.1673-9078.2019.5.006.

93. Ma K, Yu K, He YX, Li J, Wang MK. Effects of mulberry leaves water extract on lipid metabolites and intestinal flora in obese rats. West China J Pharm Sci. 2019;34(03):151-4. https://doi.org/10.13375/j.cnki. wcjps.2019.03.009.

94. Wang YQ. Bioactivity screening of polysaccharide SY01-23 isolated from Morus alba L. on human gut microbiota and the mechanism underlying the toxic effect of its main residue galacturonic acid on pancreatic $\beta$ cells. MA thesis, Nanchang University; 2020.

95. Zhang LW, Su SL, Dai XX, Wei DD, Zhu Y, Qian DW, et al. Regulatory effect of mulberry leaf components on intestinal microflora in $\mathrm{db} / \mathrm{db}$ mice. Acta Pharm Sin. 2019;54(05):867-76. https://doi.org/10.16438/j. 0513-4870.2018-0932.

96. He XY, He JJ, Zheng NN, Wang SC, Li HK. Study on anti-obesity effect and modulation of gut microbiota by Astragalus polysaccharides in mice. World Chin Med. 2016;11(11):2379-2384+2388.

97. Li Q, Liu F, Liu J, Liao S, Zou Y. Mulberry leaf polyphenols and fiber induce synergistic antiobesity and display a modulation effect on gut microbiota and metabolites. Nutrients. 2019. https://doi.org/10.3390/ nu11051017.

98. Gao WJ, Hou M, Chen XX, Wang P, Ren RG, Liu JX. Mechanism of Astragali radix vesicle-like nanoparticles for reducing blood glucose in $\mathrm{db} /$ $\mathrm{db}$ diabetic mice by regulating gut microbiota. Chin J Exp Tradit Med Formulae. 2021;27(14):111-8. https://doi.org/10.13422/j.cnki.syfjx.20211 556.

99. Zhang W. Interaction studies between flavanone glycosides and isoflavone glycosides with human intestinal bacteria, MA thesis, Nanjing University of Chinese Medicine; 2014.

100. Xiao XY. Study on the hypoglycemic effect and mechanism of astragaloside based on intestinal flora and insulin pathway, MA thesis, Shaanxi University of Science and Technology; 2020.

101. Meng Q, Bao L, Zhang Y, Zhang L, Wang ZZ, Yan D, et al. Study on hypoglycemic mechanism of combination of Berberine and Astragaloside IV based on regulation of gut microbiota. Food Drug. 2020;22(3):169-75 (CNKI:SUN:SDPK.0.2020-03-002).

102. Ding Q. The mechanism of polysaccharides from Ganoderma atrum on type 2 diabetic rats through gut microbiota [博士]: Nancang University; 2020

103. Yang K, Zhang YJ, Zhang S, Gai M, Pi XG, Hu JR, et al. Preparation of Ganderma lucidum spore oligosaccharide and its regulation on gut microbiota. Food Ferment Ind. 2020;46(09):37-42. https://doi.org/10. 13995/j.cnki.11-1802/ts.023251. 
104. Chang CJ, Lin CS, Lu CC, Martel J, Ko YF, Ojcius DM, et al. Ganoderma lucidum reduces obesity in mice by modulating the composition of the gut microbiota. Nat Commun. 2015;6:7489. https://doi.org/10.1038/ ncomms8489.

105. Wei YG, Yang HX, Zhu CH, Deng JJ, Fan DD. Hypoglycemic effect of ginsenoside Rg5 mediated partly by modulating gut microbiota dysbiosis in diabetic db/db Mice. J Agric Food Chem. 2020;68(18):5107-17. https://doi.org/10.1021/acs.jafc.0c00605.

106. Yue H, Zhou DY, Zhang MY, Zhang Y, Dai YL, Zheng F, et al. In vitro biotransformation of protopanaxtriol saponins from red ginseng by intestinal flora and its effect on intestinal flora. Chin J Appl Chem. 2021;38(03):323-30. https://doi.org/10.19894/j.issn.1000-0518.210031.

107. Chen L, Xu W, Chen D, Chen G, Liu J, Zeng X, et al. Digestibility of sulfated polysaccharide from the brown seaweed Ascophyllum nodosum and its effect on the human gut microbiota in vitro. Int J Biol Macromol. 2018;112:1055-61. https://doi.org/10.1016/j.jjbiomac.2018.01.183.

108. Cheng Y, Sibusiso L, Hou L, Jiang H, Chen P, Zhang X, et al. Sargassum fusiforme fucoidan modifies the gut microbiota during alleviation of streptozotocin-induced hyperglycemia in mice. Int J Biol Macromol. 2019;131:1162-70. https://doi.org/10.1016/j.jjbiomac.2019.04.040.

109. Deville C, Gharbi M, Dandrifosse G, Peulen O. Study on the effects of laminarin, a polysaccharide from seaweed, on gut characteristics. J Sci Food Agric. 2007;87(9):1717-25. https://doi.org/10.1002/jsfa.2901.

110. Nguyen SG, Kim J, Guevarra RB, Lee JH, Kim E, Kim SI, et al. Laminarin favorably modulates gut microbiota in mice fed a high-fat diet. Food Funct. 2016;7(10):4193-201. https://doi.org/10.1039/c6fo00929h.

111. Zhang YP, Zhao NN, Yang LH, Hong Z, Cai B, Le QQ, et al. Insoluble dietary fiber derived from brown seaweed Laminaria japonica ameliorate obesity-related features via modulating gut microbiota dysbiosis in high-fat diet-fed mice. Food Funct. 2021;12(2):587-601. https://doi.org/ 10.1039/d0fo02380a.

112. Yu XH, Zhang XR, Zhu YP, Lu GG, Liu X, Dawa LM, et al. Study on the extraction technology and vitro antibacterial activity of rhubarb anthraquinone compounds. China J Tradit Chin Med Pharm. 2018;33(11):5186-9 (CNKI:SUN:BXYY.0.2018-11-110).

113. Régnier M, Rastelli M, Morissette A, Suriano F, Le Roy T, Pilon G, et al. Rhubarb supplementation prevents diet-induced obesity and diabetes in association with increased Akkermansia muciniphila in mice. Nutrients. 2020. https://doi.org/10.3390/nu12102932.

114. Cui HX, Zhang LS, Luo Y, Yuan K, Huang ZY, Guo Y. A purified anthraquinone-glycoside preparation from rhubarb ameliorates type 2 diabetes mellitus by modulating the gut microbiota and reducing inflammation. Front Microbiol. 2019;10:1423. https://doi.org/10.3389/fmicb.2019. 01423.

115. Wang RF, Lie HY, Zang P, Du H. The effect of rhein on the gut microbiota in diabetes mice. Chin J Microecol. 2016;28(01):21-24+46. https://doi. org/10.13381/j.cnki.cjm.201601005.

116. Li L, Li R, Zhu R, Chen B, Tian Y, Zhang H, et al. Salvianolic acid B prevents body weight gain and regulates gut microbiota and LPS/TLR4 signaling pathway in high-fat diet-induced obese mice. Food Funct. 2020;11(10):8743-56. https://doi.org/10.1039/d0fo01116a.

117. Zhou B, Tian FZ, Yin ZL, Li XJ. Protective mechanism of Salvia miltiorrhiza on intestinal barrier. Chin J Digest. 2000;06:45-7 (CNKI:SUN:Z HHX.0.2000-06-022).

118. Padayachee A, Day L, Howell K, Gidley MJ. Complexity and health functionality of plant cell wall fibers from fruits and vegetables. Crit Rev Food Sci Nutr. 2017;57(1):59-81. https://doi.org/10.1080/10408398. 2013.850652

119. Li YG, Ji DF, Zhong S, Lin TB, Lv ZQ, Hu GY, et al. 1-deoxynojirimycin inhibits glucose absorption and accelerates glucose metabolism in streptozotocin-induced diabetic mice. Sci Rep. 2013;3:1377. https://doi. org/10.1038/srep01377.

120. Tian Y, Ding YP, Shao BP, Yang J, Wu JG. Interaction between homologous functional food Astragali Radix and intestinal flora. China J Chin Mater Med. 2020;45(11):2486-92. https://doi.org/10.19540/j.cnki. cjcmm.20200119.401.

121. Sun GX, Zhao YY, Miao PP, Yang XY, Miao Q, Li J, et al. Stability study in biological samples and metabolites analysis of astragaloside IV in rat intestinal bacteria in vitro. China J Chin Mater Med. 2014;39(21):425864 (CNKI:SUN:ZGZY.0.2014-21-034).
122. Yang G, Zhuo J, Lin Y, Zhang M, Liu L, Chen X, et al. Ginsenoside Rb1 prevents dysfunction of endothelial cells by suppressing inflammatory response and apoptosis in the high-fat diet plus balloon catheterinjured rabbit model via the $\mathrm{G}$ protein-coupled estrogen receptormediated phosphatidylinositol 3-kinases (PI3K)/Akt pathway. Med Sci Monit. 2019;25:7407-17. https://doi.org/10.12659/msm.912986.

123. Qomaladewi NP, Kim MY, Cho JY. Autophagy and its regulation by ginseng components. J Ginseng Res. 2019;43(3):349-53. https://doi.org/10. 1016/j.jgr.2018.12.011.

124. Nanao-Hamai M, Son BK, Komuro A, Asari Y, Hashizume T, Takayama $\mathrm{Kl}$, et al. Ginsenoside Rb1 inhibits vascular calcification as a selective androgen receptor modulator. Eur J Pharmacol. 2019;859: 172546. https://doi.org/10.1016/j.ejphar.2019.172546.

125. Atarashi K, Tanoue T, Oshima K, Suda W, Nagano Y, Nishikawa H, et al. Treg induction by a rationally selected mixture of Clostridia strains from the human microbiota. Nature. 2013;500(7461):232-6. https://doi.org/ 10.1038/nature12331.

126. de Jesus Raposo MF, de Morais AM, de Morais RM. Emergent sources of prebiotics: seaweeds and microalgae. Mar Drugs. 2016. https://doi.org/ $10.3390 /$ md14020027.

127. Patil NP, Le V, Sligar AD, Mei L, Chavarria D, Yang EY, et al. Algal polysaccharides as therapeutic agents for atherosclerosis. Front Cardiovasc Med. 2018;5:153. https://doi.org/10.3389/fcvm.2018.00153.

128. Yin J, Wang J, Li F, Yang Z, Yang X, Sun W, et al. The fucoidan from the brown seaweed Ascophyllum nodosum ameliorates atherosclerosis in apolipoprotein E-deficient mice. Food Funct. 2019;10(8):5124-39. https://doi.org/10.1039/c9fo00619b.

129. Wang X, Pei LL, Liu HB, Qv K, Xian WW, Liu J, et al. Fucoidan attenuates atherosclerosis in LDLR-/- mice through inhibition of inflammation and oxidative stress. Int J Clin Exp Pathol. 2016;9(7):6896-904.

130. Cao YJ, Pu ZJ, Tang YP, Shen J, Chen YY, Kang A, et al. Advances in bioactive constituents, pharmacology and clinical applications of rhubarb. Chin Med. 2017;12:36. https://doi.org/10.1186/s13020-017-0158-5.

131. Brkanac SR, Gerić M, Gajski G, Vujčić V, Garaj-Vrhovac V, Kremer D, et al. Toxicity and antioxidant capacity of Frangula alnus Mill. bark and its active component emodin. Regul Toxicol Pharmacol. 2015;73(3):923-9. https://doi.org/10.1016/j.yrtph.2015.09.025.

132. Chen YK, Xu YK, Zhang H, Yin JT, Fan X, Liu DD, et al. Emodin alleviates jejunum injury in rats with sepsis by inhibiting inflammation response. Biomed Pharmacother. 2016;84:1001-7. https://doi.org/10.1016/j. biopha.2016.10.031.

133. Liu PY, Yu SJ, Zhu Y, Gao TS. Effects of Rhein on resistin m RNA expression of adipose tissue and plasma free fatty acid in diabetic obese rats. Chin J Diabetes. 2011;19(05):347-9 (CNKI:SUN:ZGTL.0.2011-05-012).

134. Wan XH, Wang YL, Zhou CZ, Guo H, Ma S, Wang YZ. Research progress on chemical constituents and pharmacological effects on Salvia miltiorrhiza. Chin Tradit Herbal Drugs. 2020;51(03):788-98 (CNKI:SUN:Z CYO.0.2020-03-032)

135. Meng C, Zhuo XQ, Xu GH, Liu JL. Protection of salvianolate against atherosclerosis via regulating the inflammation in rats. J Huazhong Univ Sci Technol Med Sci. 2014;34(5):646-51. https://doi.org/10.1007/ s11596-014-1331-z.

136. Liu YL, Liu GT. Inhibition of human low-density lipoprotein oxidation by Salvianolic Acid-A. Acta Pharm Sin. 2002;02:81-5. https://doi.org/10. 16438/j.0513-4870.2002.02.001.

137. Gu JF, Su SL, Guo JM, Zhu Y, Zhao M, Duan JA. The aerial parts of Salvia miltiorrhiza Bge. strengthen intestinal barrier and modulate gut microbiota imbalance in streptozocin-induced diabetic mice. J Funct Foods. 2017. https://doi.org/10.1016/j.jff.2017.06.010.

138. Han C, Jiang YH, Li W, Liu Y, Qi ZQ. Study on the antihypertensive mechanism of Astragalus membranaceus and Salvia miltiorrhiza based on intestinal flora-host metabolism. Evid Based Complement Altern Med eCAM. 2019;2019:5418796. https://doi.org/10.1155/2019/5418796.

139. Xiao S, Zhang Z, Chen M, Zou J, Jiang S, Qian D, et al. Xiexin Tang ameliorates dyslipidemia in high-fat diet-induced obese rats via elevating gut microbiota-derived short chain fatty acids production and adjusting energy metabolism. J Ethnopharmacol. 2019;241: 112032. https:// doi.org/10.1016/j.jep.2019.112032

140. Wei X, Tao J, Xiao S, Jiang S, Shang E, Zhu Z, et al. Xiexin Tang improves the symptom of type 2 diabetic rats by modulation of the 
gut microbiota. Sci Rep. 2018;8(1):3685. https://doi.org/10.1038/ s41598-018-22094-2.

141. Wu J, Nakashima S, Nakamura S, Matsuda H. Effects of Sanoshashinto on left ventricular hypertrophy and gut microbiota in spontaneously hypertensive rats. J Nat Med. 2020;74(2):482-6. https://doi.org/10.1007/ s11418-020-01387-9.

142. Li JB, Yuan HC, Zhao J, Shen XX. Effects of buyanghuanwu Decoction on intestinal flora and tmao in rats with heart failure. World J Integr Tradit West Med. 2020;15(10):1814-8. https://doi.org/10.13935/j.cnki.sjzx. 201011.

143. Sun ML, Shi JL. Research of protective effect and change of intestinal flora of buyang Huanwu Decoction plus Ruidai on ischemia-reperfusion injury rats. Chin Arch Tradit Chin Med. 2015;33(09):2274-8. https:// doi.org/10.13193/j.issn.1673-7717.2015.09.062.

144. Wu WF, Nie HF, Hu LJ, Sun YH, Luo N, Jiang CT, et al. Effect of Buyang Huanwu Decoction on gut microbiota and plasma metabolites in ischemic stroke rats with qi deficiency and blood stasis syndrome. Chin Tradit Herb Drugs. 2021;52(01):118-28 (CNKI:SUN:Z CYO.0.2021-01-016).

145. Tang YP, Duan JA, Guo S, Su SL, Qian DW, Guo JM. Speculations on relationship between dosage and effect of prescriptions. J Nanjing Univ Tradit Chin Med. 2009;25(01):21-2326 (CNKI:SUN:N JZY.0.2009-01-005).

146. Han C, Jiang YH, Li W. Research progress of Astragali Radix and Salviae Miltiorrhizae Radix on improving renal damage in hypertension. Chin J Exp Tradit Med Formulae. 2019;25(12):214-20. https://doi.org/10 13422/j.cnki.syfjx.20191105.

147. Yin XJ, Ma XJ, Wang L, Gong LL, Fan MQ, Li L, et al. Anti-atherosclerosis mechanism of Sanhuang Xiexintang in activating blood and resolving stasis formula in vitro. Chin J Exp Tradit Med Formulae. 2018;24(22):838. https://doi.org/10.13422/j.cnki.syfjx.20182215.

148. Li J, Zhu HH, Pang YL, Yang D, Wang DL, Wang YY, et al. Study of Dahuang-Huanglian-Xiexin decoction combined with conventional western medicine in patients with type 2 diabetes. Int J Tradit Chin Med. 2019:12:1301-5. https://doi.org/10.3760/cma.j.issn.1673-4246. 2019.12.005.

149. Zhang H, Liang WJ, Ma ZX, Ye SL. Clinical study on effects of Buyang Huanwu Decoction on coronary heart disease. Chin J Integr Tradit West Med. 1995;04:213-5 (CNKI:SUN:ZZXJ.0.1995-04-006).
150. Chen KY, Wu KC, Hueng DY, Huang KF, Pang CY. Anti-inflammatory effects of powdered product of Bu Yang Huan Wu decoction: possible role in protecting against transient focal cerebral ischemia. Int J Med Sci. 2020;17(12):1854-63. https://doi.org/10.7150/ijms.46581.

151. Zhang XD. Curative effect observation of modified Buyang Huanwu Decoction in treatment of angina of coronary heart and its effect on serum HS-CRP and Hcy, MA thesis, Heilongjiang University of Chinese Medicine; 2020.

152. Lee SJ, Kim KM, Namkoong S, Kim CK, Kang YC, Lee H, et al. Nitric oxide inhibition of homocysteine-induced human endothelial cell apoptosis by down-regulation of p53-dependent Noxa expression through the formation of S-nitrosohomocysteine. J Biol Chem. 2005;280(7):5781-8. https://doi.org/10.1074/jbc.M411224200.

153. Liu YH, Qiu SH, You Y, Yang D, Peng X. Effect of Buyanghuanwu Decoction on preventing atherosclerosis induced by Hcy via Inhibiting NF-KB-dependent pathway. Chin Pharm J. 2012;47(02):104-8 (CNKI:SU $\mathrm{N}: Z G Y X .0 .2012-02-007)$.

154. Zheng YC, Lu WX, Lu N. Efficacy and Safety of Buyang Huanwu Decoction in treating angina pectoris of coronary heart disease with qi deficiency and blood stasis: a meta-analysis. Chin I Integr Med Cardio-Cerebrovasc Dis. 2021;19(09):1469-75 (CNKI:SUN:ZYYY.0.2021-09-007).

155. Lu XH, Zhang Y. Ding's experience in treating coronary heart disease with the method of "tonifying Qi, resolving blood stasis and relieving toxin." J Shandong Univ Tradit Chin Med. 2013;37(04):294-6. https://doi. org/10.16294/j.cnki.1007-659x.2013.04.016.

156. Bi FY, Wang XL, Zhao ZQ, Hou YZ, Wang S, Zhao GY, et al. Clinical epidemiological investigation on current syndrome characteristics of coronary heart disease in Chinese medicine. J Tradit Chin Med. 2017;58(23):2013-9. https://doi.org/10.13288/j.11-2166/r.2017.23.009.

\section{Publisher's Note}

Springer Nature remains neutral with regard to jurisdictional claims in published maps and institutional affiliations.
Ready to submit your research? Choose BMC and benefit from:

- fast, convenient online submission

- thorough peer review by experienced researchers in your field

- rapid publication on acceptance

- support for research data, including large and complex data types

- gold Open Access which fosters wider collaboration and increased citations

- maximum visibility for your research: over 100M website views per year

At BMC, research is always in progress.

Learn more biomedcentral.com/submissions 